\title{
The Real Effects of Financial Markets: The Impact of Prices on Takeovers
}

\author{
ALEX EDMANS, ITAY GOLDSTEIN, and WEI JIANG**
}

\begin{abstract}
Using mutual fund redemptions as an instrument for price changes, we identify a strong effect of market prices on takeover activity (the "trigger effect"). An interquartile decrease in valuation leads to a seven percentage point increase in acquisition likelihood, relative to a $6 \%$ unconditional takeover probability. Instrumentation addresses the fact that prices are endogenous and increase in anticipation of a takeover (the "anticipation effect"). Our results overturn prior literature that finds a weak relation between prices and takeovers without instrumentation. These findings imply that financial markets have real effects: They impose discipline on managers by triggering takeover threats.
\end{abstract}

DOES A LOW MARKET valuation make a firm a takeover target? In theory, if acquisition prices are related to market prices, acquirers can profit from taking over a firm whose market value is low relative to its peers-due either to mispricing or mismanagement-and restore it to its potential. Indeed, in practice, acquirers and other investors appear to track a firm's valuation multiples for indications on the potential for acquisition, and managers strive to maintain high market valuations to prevent a hostile takeover. Understanding whether such a link exists is important because, if so, this would suggest that the market is not a sideshow, but rather exerts a powerful disciplinary effect on firm management (as suggested by Marris (1964), Manne (1965), and Jensen (1993)).

Despite the above logic, existing empirical studies on takeovers fail to systematically uncover a meaningful relationship between market valuations

\footnotetext{
*Edmans is from The Wharton School, University of Pennsylvania, NBER, and ECGI. Goldstein is from The Wharton School, University of Pennsylvania. Jiang is from Columbia Business School. For helpful comments and discussions, we thank the Editor (Cam Harvey), two anonymous referees, an Associate Editor, Jack Bao, Thomas Bates, Jonathan Berk, Philip Bond, Jess Cornaggia, Todd Gormley, Dirk Hackbarth, Ayla Kayhan, Alexander Ljungqvist, Ernst Maug, Konrad Menzel, Randall Morck, Stew Myers, Lalitha Naveen, Gordon Phillips, Michael Roberts, Jacob Sagi, Jeremy Stein, and seminar participants at Columbia, Drexel, Georgia State, HBS, HEC Paris, HKUST, Houston, Mannheim, MIT Sloan, SUNY Binghamton, Temple, Tilburg, UNC, UT Dallas, Yale, AFA, Caesarea Center Conference, FIRS, LSE Paul Woolley Center Conference, NBER, the UBC Summer Conference, and the Washington University Conference on Corporate Finance. Robert Ready and Carrie Wu provided valuable research assistance. Edmans gratefully acknowledges the Goldman Sachs Research Fellowship from the Rodney White Center for Financial Research. This paper was previously circulated under the title "Takeover Activity and Target Valuations: Feedback Loops in Financial Markets."
} 
and takeover probabilities. While Cremers, Nair, and John (2009) and Bates, Becher, and Lemmon (2008) find a negative (but economically insignificant) relation between takeover likelihood and Tobin's $Q$, Palepu (1986) and Ambrose and Megginson (1992) uncover no link and Rhodes-Kropf, Robinson and Viswanathan (2005) document that market-to-book ratios of targets are in fact higher than those of control firms. Agrawal and Jaffe (2003) further find that targets do not exhibit inferior prior stock performance to peer firms. These results cast doubt on the received wisdom that market valuations create a takeover threat that forces managers to improve firm performance.

We argue that there is a fundamental challenge to finding a relation between market prices and takeover activity in the data. While markets may exhibit a trigger effect, whereby a decrease in market valuation due to mispricing or mismanagement induces a takeover attempt, market prices are endogenous and affected by other factors that may attenuate the above relationship and make it difficult to detect empirically. There are three potential sources of endogeneity. First, an anticipation effect may lead to reverse causality from takeover activity to market valuations, with forward-looking prices inflated by the probability of a future takeover. Second, there may be omitted variables correlated with both takeover probabilities and market valuations. For example, if a technology shock creates the potential for synergies, it may increase a firm's probability of becoming a takeover target and its market price at the same time. In both of the above cases, even if a low valuation attracts an acquisition, a high valuation may indicate that an acquisition is probable, thus attenuating any relationship between valuation and takeover probability in the data. Third, there may be measurement error. As indicated in the opening paragraph, we hypothesize that the true driver of takeover attempts is a decline in a firm's market valuation below its potential-due either to mispricing or mismanagement. A firm's raw market valuation is quite different from the firm's valuation discount and thus likely an inaccurate measure of it, biasing the measured coefficient toward zero.

In this paper, we adopt a new approach that represents a first step toward overcoming the above endogeneity issues and cleanly identifying the trigger effect from market prices to takeover activity. Our approach consists of two major deviations from the existing literature. First, prior literature studies the effect of raw valuations (such as price-to-earnings or market-to-book ratios) on takeover likelihood. However, a low raw valuation may not indicate underperformance and thus a need for a corrective action, as it may be driven by irremediably low quality (e.g., because the firm is mature and in a competitive industry). We thus construct a "discount" measure of the difference between a firm's current market valuation and potential value. This discount aims to measure undervaluation due to mismanagement or mispricing, and in turn the value that an acquirer can create by restoring a firm to its potential. Therefore, it has a theoretical link to the likelihood that a firm becomes targeted by a bidder. We estimate a firm's potential value using tools from the literature on stochastic frontier analysis, based on the values of other firms in the industry or with similar basic fundamentals. 
Second, we employ an instrumental variable that directly affects the market price, but that affects takeover probability only via its effect on the market price. Conceptually, this is a difficult problem: any variable that is directly associated with the firm's characteristics or management would not qualify as an instrument since it is directly related to both the price and the probability of a takeover. Hence, while the trigger effect is based on the idea that price decreases due to either mismanagement or mispricing will induce a takeover attempt, identifying it requires a measure of mispricing alone, that is, a variable that changes the price but not due to issues related to the firm's fundamentals or management.

Friction-driven mispricing events have been the subject of a large recent literature in finance, as summarized by Duffie (2010) in his presidential address to the American Finance Association. Building on this literature, we construct a measure of price pressure induced by mutual funds not due to informational reasons but rather to flows they face from investors. The idea follows from Coval and Stafford (2007), who document that large flows by mutual fund investors lead prices of stocks held by the funds to shift away from fundamental value for prolonged periods of time. While Coval and Stafford (2007) investigate actual trades executed by mutual funds, they may not be a valid instrument in our context if funds are trading deliberately based on private information on a firm's likely takeover potential. We instead study mutual funds' hypothetical trades mechanically induced by flows by their own investors. We argue that fund investors' decisions to accumulate or divest mutual fund shares are unlikely to be directly correlated with the takeover prospects of individual firms held by the fund. An investor who wishes to speculate on the takeover likelihood of an individual firm will trade the stock of that firm rather than a mutual fund share. ${ }^{1}$ Hence, investor flows lead to price pressure that may affect the probability of a takeover but are not directly motivated by this probability. We find that our measure causes significant price changes followed by slow reversal that ends with full correction only after about 2 years.

Our analysis uncovers a statistically and economically significant effect of market prices on takeover probabilities. First, our discount measure exhibits a more significant correlation with takeover probabilities than the valuation measures used previously in the literature: an interquartile change in the discount is associated with a one percentage point increase in takeover probability in the following year. Second, our main result shows that, by accounting for the endogeneity of the discount and instrumenting it with mutual fund investors' flows, the trigger effect rises substantially: an interquartile change in the discount causes a seven percentage point increase in takeover probability in the following year. This is both statistically significant and economically important relative to the $6.2 \%$ unconditional probability that an average firm receives a takeover bid in a particular year.

\footnotetext{
${ }^{1}$ Importantly, we exclude mutual funds that specialize in specific industries, to ensure that investors' flows are not driven by a takeover wave among many firms held by the fund.
} 
We also use our results to shed light on the determinants of market prices in equilibrium. Inspecting the gap between the equilibrium correlation between discounts and takeover probabilities and the causal effect of discounts on takeover probabilities (i.e., comparing our estimated trigger effects without and with instrumentation), our results imply that, for the average firm, a one percentage point increase in the probability of a takeover next year reduces the current discount by 1.2 percentage points. Since takeover premium is, on average, $40 \%$ of market value, one-third of this estimated decrease in discount $(0.4$ percentage points) can be directly attributed to the anticipation of a takeover in the following year. The remainder could result from other factors, such as the technology-driven synergies mentioned above or anticipation of takeovers in future years.

Our findings have a number of implications for takeover markets. First and foremost, the trigger effect implies that financial markets are not just a sideshow. They have a real effect on corporate events such as takeovers and thus on firm value. In this respect, our paper adds to existing evidence on the real effects of financial markets, such as Baker, Stein, and Wurgler (2003) and Chen, Goldstein, and Jiang (2007). ${ }^{2}$ While these previous papers identify real effects via comparative statics (showing that the sensitivity of real decisions to prices increases in some firm characteristic that is hypothesized to augment the importance of prices), our paper identifies it directly. In particular, we are the first to use an instrumental variable to capture the effect of exogenous price changes on corporate events.

In general, market prices will affect takeover activity if they are related to expected future acquisition prices. This may happen for a couple of reasons. First, as in models by Fishman and Hagerty (1992), Dow and Gorton (1997), and Goldstein and Guembel (2008), decision makers may learn from market prices to guide their actions. In a takeover context, this argument is more complex. For prices to affect takeover likelihood (rather than just the price paid in a takeover), there must be an asymmetry in learning between the acquirer and the target's shareholders. For example, suppose that target shareholders learn the firm's true value from the market price and thus demand a takeover price that is closely linked to the market price (e.g., a certain premium above market price), ${ }^{3}$ but the acquirer has additional information on the firm's potential value under his management and so the value of the target to him is less sensitive to the market price. In this case, a decrease in target valuation will increase the potential gain for the acquirer and thus the likelihood of a bid. Note that to date the possibility of asymmetric learning has not yet been incorporated into the theoretical takeover literature. Our empirical findings thus call for a modification of the existing takeover theories. Second, market participants may anchor on the price, as in Baker, Pan, and Wurgler (2012). For example,

\footnotetext{
${ }^{2}$ For an early discussion, see Morck, Shleifer, and Vishny (1990).

${ }^{3}$ Schwert (1996) provides related evidence, finding that the offer price increases almost dollarfor-dollar with the target's pre-bid runup. He argues that the higher offer price may be justified by the target's greater perceived value based on new information from the runup. He does not explore the effect on takeover probability.
} 
practitioners often study premia to the market price in related past deals to estimate an appropriate premium to offer in the current transaction (known as "precedent transactions analysis").

Interestingly, the active role of financial markets implies that any factor that influences prices can also influence takeover activity (and other real actions). Therefore, mispricing (e.g., due to market frictions or investor errors) can have real consequences by impacting takeovers. Our paper is therefore related to the behavioral corporate finance literature (surveyed by Baker, Ruback, and Wargler (2007)). In particular, Dong et al. (2006) use a firm's multiple as an indicator for mispricing and link it to takeover activity. Unlike us, they do not model the relationship between prices and takeovers as a simultaneous system or use an instrumental variable to identify the effect of exogenous price changes, but instead focus on the equilibrium correlation between the valuation multiples and takeovers. Note that, in the behavioral corporate finance literature, temporary overvaluation often improves a firm's fundamental value as it allows managers to raise capital or undertake acquisitions at favorable prices (e.g., Stein (1996), Shleifer and Vishny (2003)). Here, it can reduce fundamental value by deterring value-creating takeovers.

Second, regarding the anticipation effect, our results demonstrate the illusory content of stock prices. While researchers typically use valuation measures to proxy for management performance, a firm's stock price may not reveal the full extent of its agency problems, as it may also incorporate the expected correction of these problems via a takeover. Our results thus challenge the common practice of using Tobin's $Q$ or stock price performance to measure management quality. By breaking the correlation between market valuations and takeover activity into trigger and anticipation effects, our analysis allows us to determine the extent to which future expected takeovers are priced in. In that respect, our paper is related to Song and Walkling (2000), who find that firms' stock prices increase following the acquisition of their rivals and attribute this to the increased expectation that they will be taken over themselves. Other papers analyze the effect of takeover anticipation on stock returns rather than valuations. Hackbarth and Morellec (2008) and Cremers, Nair, and John (2009) show that anticipated takeovers affect the correlation of a stock's return with the market return and hence have an effect on the discount rate. Prabhala (1997) and Li and Prabhala (2007) note that takeover anticipation will affect the market return to merger announcements.

Third, considering the full feedback loop-the combination of the trigger effect and the anticipation effect-our results suggest that the anticipation effect could become an impediment to takeovers. The anticipation of a takeover boosts prices, deterring the acquisition of underperforming firms. Moreover, it may also allow managers to underperform in the first place since they are less fearful of disciplinary acquisitions. ${ }^{4}$ Indeed, many practitioners believe that

\footnotetext{
${ }^{4}$ Brealey, Myers, and Allen (2010) note that "the most important effect of acquisitions may be felt by the managers of companies that are not taken over. Perhaps the threat of takeover spurs the whole of corporate America to try harder."
} 
the anticipation effect has significant effects on real-life takeover activity. A December 22, 2005 Wall Street Journal article claims that this has been a major problem in the U.S. banking industry: "takeover potential raises [the] value of small financial institutions, making them harder to acquire." This may have led to severe consequences, as small banks remained stand-alone and were less able to withstand the recent financial crisis. Many commentators believe that the same phenomenon recently occurred in the U.K. water industry. For example, an October 13, 2006 article in This Is Money notes that "there are concerns that the race for control of [water] assets has overheated valuations, adding to speculation that the [merger] bubble is about to burst." 5 Essentially, in these cases and others, the belief of an upcoming takeover becomes self-defeating. ${ }^{6}$ This self-defeating nature of takeover expectations sheds new light on other important real-world phenomena. First, it suggests why merger waves endogenously die out. If a recent spate of mergers leads the market to predict future acquisitions, this causes valuations to rise (anticipation effect), dissuading further acquisition attempts. Second, it provides a rationale for the practice of CEOs publicly expressing concerns about an upcoming takeover. Such statements act as a takeover defense, as they inflate the price, which in turn deters the takeover from occurring. We reiterate the caveat that we are only able to attribute a portion of the endogeneity to the anticipation effect; the anticipation effect that we are able to pin down is economically modest.

In addition, our paper has a number of wider implications outside the takeover market. The feedback loop may apply to other corrective actions, such as CEO replacement, shareholder activism, and regulatory intervention. Low valuations trigger intervention, but market anticipation causes prices to rise, which in turn may deter the correction from occurring. Bradley et al. (2010) show that the discount at which a closed-end fund is traded affects and reflects the probability of activism at the same time. In addition, while many existing papers use raw valuation or profitability to measure management quality or agency problems (e.g. to correlate it with CEO pay or corporate governance), this paper's approach of measuring these variables using a discount to potential value can be applied to these other settings. Furthermore, trigger effects are often estimated in non-M\&A settings, such as the link between firm valuation and CEO turnover. Our approach of purging valuations of the anticipation effect is applicable to the estimation of these trigger effects also.

More broadly, our results contribute to the growing literature that analyzes the link between financial markets and corporate events (see Bond, Edmans, and Goldstein (2012) for a recent survey). While the corporate finance literature typically studies the effect of prices on firm actions and the asset pricing literature examines the reverse relation, our paper analyzes the full feedback

\footnotetext{
${ }^{5}$ See, "Water Takeovers Bubbling Up," by This is Money, October 13, 2006. Available at: http://www.thisismoney.co.uk/money/news/article-1603327/Water-takeovers-bubbling-up.html.

${ }^{6}$ This effect is reminiscent of the free-rider problem in the theoretical model of Grossman and Hart (1980), although the market price plays no role in coordinating expectations in their setting. Equilibrium outcomes in settings where the combination of the trigger effect and the anticipation effect becomes self-defeating have been analyzed by Bond, Goldstein, and Prescott (2010).
} 
loop-the simultaneous, two-way interaction between prices and corporate actions that combines the trigger and anticipation effects. We show that prices both affect and reflect real decisions. One important strand of this literature concerns the link between financial market efficiency and real efficiency. While most existing research suggests that the former is beneficial for the latter, ${ }^{7}$ our results point to an intriguing disadvantage of forward-looking prices-they may deter the very actions that they anticipate.

The remainder of the paper is organized as follows. Section I specifies the model that we use for the empirical analysis. In Section II we describe our data and variable construction. Section III presents the empirical results. In Section IV we consider some extensions and robustness tests. Section V concludes.

\section{Model Specification}

\section{A. Firm Valuation and Discount}

A number of earlier papers study the effect of raw valuations on takeover probability. By contrast, our key explanatory variable is the "discount" at which a firm trades relative to its maximum potential value absent managerial inefficiency and mispricing, which we call the "frontier value." Theoretically, it is this variable that will drive a firm's likelihood of becoming a takeover target, as it measures the potential gain from an acquisition.

In some settings the frontier value is well defined. For example, in closedend funds, it is the net asset value (NAV). The discount can then be simply calculated as the difference between the NAV and the market price. Indeed, Bradley et al. (2010) find that activist shareholders are more likely to target closed-end funds that are trading at deeper discounts. Analogously, the market value of regular corporations can deviate from their potential value owing to agency problems and/or mispricing, and this might make the corporation a takeover target.

For a regular corporation, the frontier value cannot be observed and must be estimated. This is done by observing the valuation of "successful" firms with similar fundamentals. Specifically, let $X$ be a vector of variables representing firm fundamentals that determine potential value: $V^{*}=f(X)$. Since $V^{*}$ represents the potential value after the acquirer has corrected managerial inefficiencies, the $X$ variables should consist of firm characteristics that bidders are unlikely to change upon takeover.

If the set of value-relevant variables $X$ is exhaustive, and if there is no noise or mispricing in valuation, then the maximum valuation commanded among the group of peer firms that share the same fundamentals can be perceived as the "potential" of all other firms. However, a particular firm could have an abnormally high valuation owing to luck, misvaluation, or idiosyncratic features (such as unique core competencies) if $X$ is not fully exhaustive of

\footnotetext{
${ }^{7}$ See, for example, Fishman and Hagerty (1992), Holmstrom and Tirole (1993), Subrahmanyam and Titman (1999), Dow, Goldstein, and Guembel (2010), Admati and Pfleiderer (2009), Edmans (2009), and Edmans and Manso (2011).
} 
all value-relevant fundamental variables. For example, a rival search engine is unlikely to command the valuation of Google even if it is efficiently run. Setting the potential value to the maximum value among peers would thus erroneously result in assuming that this high valuation was achievable for all firms and overestimating the discount.

An improved specification is to set the potential value to a high percentile, rather than maximum, valuation of peer firms. We define "successful" firms as those that command valuations at the $(1-\alpha)^{\text {th }}$ percentile or higher among peer firms, where $0<\alpha<\frac{1}{2}$. A firm valued at below the $(1-\alpha)^{\text {th }}$ percentile is classified as operating below potential value. When $\alpha=0$, the benchmark is the maximum valuation among peers; when $\alpha=\frac{1}{2}$, the benchmark becomes the median (we require $\alpha<\frac{1}{2}$ to reflect the fact that a successful firm should be above median).

We now discuss the choices for the $X$ variables and the parameter $\alpha$, starting with the former. In our first approach, $X$ includes only a firm's industry affiliation. Acquirers are unlikely to change the target's sector and instead typically aim to restore its value to that commanded by successful firms in the same sector, so the industry affiliation easily satisfies the requirement for $X$ to be exogenous to acquirers' actions. In using the industry benchmark, we follow other papers in the takeover literature (see, e.g., Rhodes-Kropf, Robinson, and Viswanathan (2005)) as well as practitioners. For example, "comparable companies analysis" compares a firm's valuation to its industry peers and is often used by practitioners to identify undervalued companies that might be suitable takeover targets. The potential concern is that an industry benchmark ignores other determinants of potential value. For example, small and growing firms are likely to command higher valuations than larger, mature peers. Also, this approach implicitly assumes that a particular industry cannot be systematically over or undervalued, often contradicted by evidence (Hoberg and Phillips (2010)).

We therefore also employ a second approach, using firm characteristics as $X$ variables. ${ }^{8}$ We take two steps to reduce the concern that the estimated frontier value can be affected by the acquirer. First, following Habib and Ljungqvist (2005), who also estimate a frontier value, we choose variables that are unlikely to be radically transformed by an acquirer. For example, while a firm's market share and financial policies (such as dividend payout) both affect its actual valuation, only the former affects its frontier valuation: it is difficult to transform market share immediately, but financial policies can be quickly reversed. The $X$ variables we use are firm size, firm age, asset intensity, $R \& D$ intensity, market share, growth opportunities, and business cyclicality. These variables are further motivated in Section II.B as well as in Habib and Ljungqvist (2005).

Second, we recognize that firm characteristics are not completely exogenous and that acquirers may be able to change them within some range. Accordingly,

\footnotetext{
${ }^{8}$ We do not use industry affiliation in conjunction with firm characteristics as we wish to allow particular industries to be over- or undervalued.
} 
we do not use the raw measures of these variables (except for age, which is fully exogenous) but rather their tercile ranks. This specification allows for bidders to change the value of these fundamentals within a given tercile, but not to alter it sufficiently to move it into a different tercile. Since an acquirer is more likely to change the tercile of a firm that is currently close to the cutoffs, we exclude such firms in a sensitivity analysis in Section IV.

Indeed, existing research finds that takeover gains typically stem from correcting underperformance given a set of fundamentals rather than changing the fundamentals themselves. For the typical mergers and acquisitions (M\&A) deal, one cannot observe whether the target's fundamentals change since they are consolidated with the acquirer, but this is possible in a leveraged buyout (LBO) since the target continues to be reported independently. Muscarella and Vetsuypens (1990) find that the sales (one of our $X$ variables) of LBO targets change at a similar rate to sales of nontargets, and Smith (1990) documents no significant difference in the rate of change in R\&D (a second $X$ variable). Further, many papers find that the bulk of value creation from LBOs is due to improvements in efficiency. This literature is surveyed by Eckbo and Thorburn (2008); we briefly mention the key papers here. Kaplan (1989), Smith (1990), and Muscarella and Vetsuypens (1990) find improvements in accounting performance. Smith (1990) shows that these improvements arise from superior working capital management, and Muscarella and Vetsuypens (1990) demonstrate that they stem from cutting expenses rather than increasing revenues. Using plant-level data, Lichtenberg and Siegel (1990) document significant increases in productivity, and the case study of Baker and Wruck (1989) finds improved incentives, monitoring, and working capital management.

In summary, there is a trade-off between our two approaches. The advantage of the second approach is that a more extensive list of variables provides a more accurate assessment of true potential value. The disadvantage is that some of the added $X$ variables may not be completely outside the acquirer's control. This concern does not arise under the first approach, where the only $X$ variable is industry affiliation. As we describe later, our results turn out to be slightly stronger under the industry approach.

The remaining specification issue is the choice of $\alpha$. Here again there is a trade-off. A low $\alpha$ may overweight abnormal observations, while a high $\alpha$ may underestimate the potential value and thus the occurrence of discounts. We calibrate $\alpha$ from the empirical facts documented by prior literature. According to Andrade, Mitchell, and Stafford (2001), the median takeover premium was $37 \%$ to $39 \%$ during the 1980 to 2002 period; Jensen and Ruback (1983) document similar magnitudes in an earlier period. Since bidder returns are close to zero on average (Jensen and Ruback (1983), Betton, Eckbo, and Thorburn (2008)), the target captures almost the entire value gains from the takeover. Therefore, on average, the takeover premium represents the potential for value improvement at the target. We thus calibrate the $(1-\alpha)^{\text {th }}$ percentile (i.e., the expected posttakeover value) to capture the value of the median target firm 
(pretakeover) plus the median takeover premium (38\%). ${ }^{9}$ Specifically, we pool all firms within a given three-digit SIC industry across all years and subtract year fixed effects. We then add $38 \%$ to the pre-acquisition equity value of each firm that was a takeover target and rank each target's cum-premium value within its industry peers. We find that after including the premium, the median ranking of targets in our sample is at the $77^{\text {th }}$ percentile of the respective industry. Rounding to the nearest decile, this corresponds to an $\alpha$ of $20 \%$. In other words, about $80 \%(20 \%)$ of the firms are traded at a discount (premium) in a given year. This choice of $\alpha$ is also supported by evidence from closed-end funds, a setting in which the discount can be precisely measured. Bradley et al. (2010) find that, on average, about $20 \%$ (80\%) of closed-end funds trade at a premium (discount) to NAV. In Section IV, we vary $\alpha$ across the range of $[0.10,0.30]$ and find that our results are not sensitive to the choice of $\alpha$ within this region.

Once $X$ and $\alpha$ are chosen, and given observed valuations $V$, the potential value can be estimated using the quantile regression method pioneered by Koenker and Bassett (1978):

$$
V=X \beta+\varepsilon,
$$

where uantile $_{1-\alpha}(\varepsilon)=0, \varepsilon$ is a disturbance term, and $X \beta$ is the potential value. More specifically, with actual data $\left\{V_{i, t}, X_{i, t}\right\}$ and for a given $\alpha$, we estimate $\widehat{\beta}$ in (1) via the least absolute deviation (LAD) method:

$$
\begin{gathered}
\min _{\widehat{\beta} \in \mathcal{B}} \frac{1}{n}\left\{\sum_{V_{i, t}>f\left(X_{i, t} ; \widehat{\beta}\right)}(1-\alpha)\left|V_{i, t}-f\left(X_{i, t} ; \widehat{\beta}\right)\right|+\sum_{V_{i, t} \leq f\left(X_{i, t}, \widehat{\beta}\right)} \alpha\left|V_{i, t}-f\left(X_{i, t} ; \widehat{\beta}\right)\right|\right\}, \\
\text { s.t. } f\left(X_{i, t} ; \widehat{\beta}\right) \geq 0,
\end{gathered}
$$

where $f\left(X_{i, t} ; \widehat{\beta}\right)$ is the estimated maximum potential value. Note that $(2)$ holds regardless of the distribution of $\varepsilon$ (or its empirical analog $V_{i, t}-f\left(X_{i, t} ; \widehat{\beta}\right)$ ), and so we do not require any assumptions over the disturbance term, except for its value at the $(1-\alpha)^{\text {th }}$ percentile. The added nonnegativity constraint $f\left(X_{i, t} ; \widehat{\beta}\right) \geq$ 0 (which reflects limited liability) is a minor variation of the original model of Koenker and Bassett (1978). The nonnegativity constraint is addressed by the censored least absolute deviation (CLAD) method of Powell (1984). Obviously, this estimation is simple under the first approach, where there is a single $X$ variable, industry affiliation. In this case, the frontier value is simply the $80^{\text {th }}$ percentile firm in the industry.

Having estimated $\widehat{\beta}$, the empirical analog to Discount $=\left(V^{*}-V\right) / V^{*}$ is

$$
\left(X_{i, t} \widehat{\beta}-V_{i, t}\right) / X_{i, t} \widehat{\beta} .
$$

\footnotetext{
${ }^{9}$ Arguably, the takeover premium might include synergy as well as efficiency gains. According to Betton, Eckbo, and Thorburn (2008), same-industry takeovers (where synergies are most likely) do not involve higher takeover premia, and hostile takeovers (which are less likely to be synergydriven) do not feature lower premia. Therefore, valuation-driven takeovers likely exhibit similar premia to takeovers in general.
} 
Our estimation of the potential value is a form of the stochastic frontier method proposed by Aigner, Lovell, and Schmidt (1977) and analyzed by Kumbhakar and Lovell (2000). A different form of stochastic frontier analysis has been used in finance by Hunt-McCool, Koh, and Francis (1996) and Habib and Ljungqvist (2005). Our specification (1) makes no parametric assumptions regarding $\varepsilon$ and thus accommodates skewness, heteroskedasticity, and within-cluster correlation, all of which are common features in finance panel data.

We emphasize that the frontier value is a standalone concept, and deliberately does not take into account any synergies with specific acquirers. This is because our goal is to study the effect of prices on takeover activity, and more generally the importance of financial markets for real decisions. If synergies are the primary motive for mergers and/or financial markets are a sideshow, our Discount measure (which ignores acquirer-specific synergies and captures only managerial inefficiency and mispricing) should have no explanatory power. By contrast, we find that standalone Discount does attract takeovers. ${ }^{10}$

\section{B. Interaction of Takeover and Discount}

Our goal is to estimate the effect of the discount on takeover likelihood. We will show that accounting for the endogeneity of the discount is crucial in quantifying the trigger effect from the discount to the takeover likelihood. To ease the exposition, we hereforth refer to one source of endogeneity in the discount, namely, the anticipation effect (from the takeover likelihood to the discount). In Section III.B.2, we discuss how much of the endogeneity can indeed be accounted for by the anticipation effect.

Let us start with a benchmark model in which the discount is exogenous to the takeover likelihood, that is, the discount only affects the takeover likelihood. We use Discount ${ }^{0}$ to denote the "underlying" discount that would exist in such a world. In this benchmark model, the system can be written as

$$
\begin{aligned}
& \text { Discount }^{0}=\gamma_{0} X+\gamma_{1} Z_{1}+\gamma_{2} Z_{2}+\eta, \\
& \text { Takeover }^{*}=\mu_{1} \text { Discount }^{0}+\mu_{2} X+\mu_{3} Z_{1}+\xi, \\
& \text { Takeover }= \begin{cases}1, & \text { if Takeover } \\
0, & \text { otherwise, }\end{cases} \\
& \operatorname{corr}(\eta, \xi)=0,
\end{aligned}
$$

${ }^{10}$ Note that, to the extent that other peer firms have already merged and achieved synergies, our measure does capture these potential synergies. In addition, the takeover premium used to calibrate $\alpha=0.2$ is based on transactions that likely involved synergies. The synergies that our measure does not capture are those that are not reflected in the current value of comparable firms and are specific to a combination with a particular acquirer. 
where Takeover* is the latent variable for the propensity of a takeover bid, and Takeover is the corresponding observed binary outcome. Since $\operatorname{corr}(\eta, \xi)=0$, the two equations can be separately estimated using a linear regression model and a binary response regression model, respectively.

We classify determinants of the discount into two groups. The vector $Z_{1}$ comprises variables that affect both the discount and the probability of takeover. These include variables that capture managerial agency problems, as they affect operational inefficiency and are likely also correlated with takeover resistance. The variable $Z_{2}$ represents market frictions that affect the stock price but have no independent effect on takeover probability other than through the price. The distinction between the $Z_{1}$ and $Z_{2}$ variables will become important when we consider the endogeneity of the discount and require instruments.

Since the discount is calculated using tercile ranks of $X$ (except Age, which enters with its full value), it is not orthogonal to the raw values of $X$ and so $X$ (except Age) appears in (4). We also allow the $X$ variables to enter the Takeover equation directly as certain firm characteristics may make an acquisition easier to execute. For example, small acquisitions are easier to finance and less likely to violate antitrust hurdles (Palepu (1986), Mikkelson and Partch (1989)). In addition, it is easier to raise debt to finance targets with steady cash flows, high asset tangibility, and in noncyclical businesses. All variables are described in Section II.B.

Allowing for the endogeneity of the discount, the equations above become interdependent. Specifically, if the endogeneity is due to the market rationally anticipating the probability of a takeover, then the observed discount (Discount) will shrink below the underlying Discount ${ }^{0}$ as modeled by (4). In this case, (4) and (5) should be remodeled as

$$
\text { Discount }=\gamma_{0} X+\gamma_{1} Z_{1}+\gamma_{2} Z_{2}+\delta \xi+\eta^{\prime},
$$

$$
\text { Takeover }^{*}=\mu_{1} \text { Discount }+\mu_{2} X+\mu_{3} Z_{1}+\xi,
$$

where $\eta$ in (4) becomes $\delta \xi+\eta^{\prime}$ in (8), with $\delta \xi$ representing the shrinkage from the anticipation effect, that is, $\delta$ is expected to be negative. As a result, we have

$$
\begin{aligned}
\rho= & \operatorname{corr}(\eta, \xi)=\operatorname{corr}\left(\delta \xi+\eta^{\prime}, \xi\right)=\delta \sigma_{\xi}^{2} \\
& <0 \text { if } \delta<0,
\end{aligned}
$$

and hence the simultaneity of the system. Note that since $\rho<0$, the endogeneity acts in the opposite direction from the true $\mu_{1}$ and using equation (9) alone will underestimate $\mu_{1}$. In other words, empiricists might estimate a low $\mu_{1}$ simply because a low discount is observed when the market anticipates a takeover. The only way to uncover the true $\mu_{1}$ is by using an instrumental variable $Z_{2}$ that has a direct effect on Discount but only affects Takeover* via its effect on Discount.

The system cannot be estimated using conventional two-stage least squares 
because the observed variable Takeover is a binary variable. Our estimation follows Rivers and Vuong (1988) and adopts the maximum likelihood method. We estimate (9) as the main equation, using the reduced form of (8) as an input to the main equation, and instrumenting the endogenous variable Discount by the $Z_{2}$ variable. Later, we back out the relation from Takeover shocks to Discount in (8) from the estimation (see Section III.B).

The intuition of the estimation is as follows. Suppose we obtain the residual discount, Discount, from the linear regression as specified in (8):

$$
\widehat{\text { Discount }}=\text { Discount }-\widehat{\gamma_{0}} X-\widehat{\gamma_{1}} Z_{1}-\widehat{\gamma_{2}} Z_{2}=\delta \xi+\eta^{\prime}
$$

Having controlled for the observable determinants of the discount, the residual discount Discount consists of two components: the anticipation effect $(\delta \xi)$ and an unmodeled residual disturbance $\left(\eta^{\prime}\right)$. The power of the test rests on the explanatory power of $X, Z_{1}$, and $Z_{2}$ so that, within Discount, the unmodeled residual $\eta^{\prime}$ (which is not correlated with any other variables in the model) does not dominate the anticipation effect $\delta \xi$. The residual in (9), $\xi$, can be expressed as a linear function of Discount as follows:

$$
\xi=\lambda \widetilde{\text { Discount }}+\xi^{\prime}
$$

Substituting (12) into (9) yields

$$
\text { Takeover }^{*}=\mu_{1} \text { Discount }+\mu_{2} X+\mu_{3} Z_{1}+\underbrace{\widehat{\lambda \text { Discount }}+\xi^{\prime}}_{=\xi} .
$$

By adding the projected residual, Discount, as a control function (or "auxiliary" regressor) in equation (13), it "absorbs" the correlation between the error term and the Discount regressor. Therefore, the resulting residual $\xi^{\prime}$ is now a well-behaved disturbance that is uncorrelated with all other regressors in the Takeover equation, including Discount. As a result, (13) resembles a regular probit specification except that Discount, which is not a natural covariate, needs to be integrated out in order to obtain the structural coefficients on the observable variables. Equation (B3) in Appendix B presents the full likelihood function.

\section{Data and Variable Description}

\section{A. Data}

We obtain data on M\&A from Securities Data Company (SDC) for 1980 to 2007. We include all bids, regardless of whether they are eventually completed, since the target's valuation is likely to have greatest effect on an acquirer's decision to bid; we repeat the analysis with completed bids only at the end of Section IV.C. Since we are assuming a sufficient change of control that 
the acquirer is able to improve the target's efficiency, we use SDC's "Form of the Deal" variable to exclude bids classified as acquisitions of partial stakes, minority squeeze-outs, buybacks, recapitalizations, and exchange offers. We also delete bids for which the acquirer had a stake exceeding $50 \%$ before the acquisition, or a final holding of under 50\%. This leaves us with 13,196 deals. As we require the target's valuation, we drop all bids for which the target does not have stock return data on CRSP and basic accounting data on Compustat. We also exclude all financial (SIC code 6000-6999) and utilities (SIC code 40004949) firms from the sample, because takeovers are highly regulated in these industries. These restrictions bring the final sample down to 6,555 deals. From this list we construct the variable Takeover, a dummy variable that equals one if the firm receives a takeover bid in a particular calendar year. The universe of potential targets is all nonfinancial and nonutility firms that have the necessary CRSP and Compustat data.

Table I, Panel A, provides a full definition of all the independent variables used in our analysis; summary statistics are in Panel B. All of our accounting variables come from Compustat; we obtain additional variables from CRSP, Thomson Reuters, and SDC as detailed later. All variables from Compustat are calculated for the fiscal year ending the year before the Takeover dummy; the others are calculated for the prior calendar year. All potentially unbounded numbers are winsorized at the $1 \%$ and $99 \%$ levels.

\section{B. Variable Description}

The construction of the Discount variable relies on the choice of a valuation metric to determine $V$ and a set of fundamental variables that can be used to predict the frontier value. Our primary valuation measure is $Q$, the ratio of enterprise value (debt plus market equity) to book value (debt plus book equity), as it is the most widely used valuation metric in the finance literature. We also use a secondary measure, $E V / E b i t d a$, the ratio of enterprise value to earnings before interest, tax, depreciation, and amortization, because most takeovers are driven by the acquirer's desire to access the target's cash flows rather than liquidate target assets. In addition, this variable is frequently used by M\&A practitioners. Negative values for these observations are coded as missing.

We describe the rationale behind the choice of $X$ variables in Section I.A. In our first specification, the only $X$ variable is a firm's industry affiliation as classified by the three-digit SIC code. Therefore, the frontier value is the $80^{\text {th }}$ percentile valuation of a given industry. To construct this measure, we first pool observations from all years for a given industry, filter out year fixed effects from the valuation measures, retrieve the $80^{\text {th }}$ percentile value, and then add back the year fixed effects. ${ }^{11}$ Finally, we calculate Discount as in (3), which is

\footnotetext{
${ }^{11}$ We pool observations from all years for a given industry (while adjusting for year fixed effects) to have a sufficiently large sample to form accurate percentile estimates. On average, there are 26 observations in an industry-year, and 693 observations in an industry across all years from 1980 to 2006 .
} 
Table I

\section{Summary of Variables}

This table summarizes the main variables used (Panel A) and presents summary statistics (Panel B). All data are obtained from Compustat unless otherwise stated; "data" numbers refer to the line items from Compustat.

\section{Panel A: Data Definitions}

Discount Variables (Discount)
Discount (Industry:
EV/Ebitda)
Discount (Industry: Q)
Discount (Firm:
EV/Ebitda)
Discount (Firm: Q)
Fundamental Variables $(X)$
Age
ATO
BetaAsset
Growth
MktShr
R\&D
SalesRank

Value discount relative to the industry frontier, using EV/Ebitda as the valuation metric.

Value discount relative to the industry frontier, using $Q$ as the valuation metric.

Value discount relative to the firm-specific frontier, using EV/Ebitda as the valuation metric.

Value discount relative to the firm-specific frontier, using $\mathrm{Q}$ as the valuation metric.

Firm age, calculated as years from first appearance in CRSP. Asset turnover. Sales (data12)/Assets (data6).

Beta on the market factor in a Fama-French three-factor model using daily data from CRSP, and then unlevered.

Average sales growth during past (up to) 3 years.

Sales / Total sales in three-digit SIC industry.

R\&D expense (data46)/Sales (data12); zero if missing.

Rank of sales (data12) among all Compustat firms in a given year, ranging from zero to one.

Variables Affecting Discount and Takeover Probability $\left(Z_{1}\right)$

Amihud

Illiquidity measure per Amihud (2002); yearly average of the square root of (Price $\times$ Vol)/|Return|.

Daily observations with a zero return are removed; coded as missing if $<30$ observations in a year, from CRSP.

HHIFirm

HHISIC3

Herfindahl index of a firm's sales in different business segments.

Inst

Herfindahl index of sales by all firms in three-digit SIC industry.

$\%$ of shares outstanding held by institutions, from Thomson Financial.

Leverage

(Debt (data9 + data34) - Cash (data1))/Assets (data 6).

Payout

(Dividends (data21) + Repurchases (data115))/Net Income (data18); zero if numerator is zero or missing, and one if numerator $>0$ and denominator $=0$.

Variables Affecting Discount $\left(Z_{2}\right)$ MFFlow

Mutual fund price pressure, from Thomson Reuters mutual fund holdings database. See the Appendix for further details.

Panel B: Summary Statistics

Percentiles

\begin{tabular}{lrrrrrrrr} 
Name & \# Obs & Mean & Std. Dev. & $5^{\text {th }}$ & $25^{\text {th }}$ & $50^{\text {th }}$ & $75^{\text {th }}$ & $95^{\text {th }}$ \\
\hline Age & 118,942 & 11.48 & 13.03 & 1 & 3 & 7 & 15 & 37 \\
ATO & 118,942 & 1.21 & 0.82 & 0.17 & 0.63 & 1.08 & 1.59 & 2.79 \\
Amihud & 101,026 & 0.77 & 1.11 & 0.02 & 0.11 & 0.35 & 0.93 & 3.05 \\
\hline
\end{tabular}


Table I-Continued

\begin{tabular}{|c|c|c|c|c|c|c|c|c|}
\hline \multicolumn{9}{|c|}{ Panel B: Summary Statistics } \\
\hline \multirow[b]{2}{*}{ Name } & \multirow[b]{2}{*}{ \# Obs } & \multirow[b]{2}{*}{ Mean } & \multirow[b]{2}{*}{ Std. Dev. } & \multicolumn{5}{|c|}{ Percentiles } \\
\hline & & & & $5^{\text {th }}$ & $25^{\text {th }}$ & $50^{\text {th }}$ & $75^{\text {th }}$ & $95^{\text {th }}$ \\
\hline BetaAssets & 117,211 & 0.69 & 0.41 & 0.09 & 0.38 & 0.65 & 0.95 & 1.45 \\
\hline $\begin{array}{l}\text { Discount (Industry: } \\
\text { EV/Ebitda) }\end{array}$ & 92,116 & 0.18 & 0.48 & -1.05 & 0.10 & 0.38 & 0.57 & 0.76 \\
\hline Discount (Industry: Q) & 116,543 & 0.24 & 0.47 & -0.90 & 0.09 & 0.37 & 0.57 & 0.77 \\
\hline $\begin{array}{l}\text { Discount (Firm: } \\
\text { EV/Ebitda) }\end{array}$ & 92,141 & 0.27 & 0.48 & -1.03 & 0.11 & 0.41 & 0.61 & 0.79 \\
\hline Discount (Firm: Q) & 116,567 & 0.28 & 0.46 & -0.92 & 0.11 & 0.41 & 0.60 & 0.77 \\
\hline EV/Ebitda & 92,141 & 15.95 & 28.05 & 3.76 & 6.12 & 8.70 & 13.77 & 47.05 \\
\hline Growth (\%) & 118,942 & $30.4 \%$ & $80.0 \%$ & $-17.8 \%$ & $1.3 \%$ & $11.4 \%$ & $28.3 \%$ & $127.5 \%$ \\
\hline HHIFirm & 118,942 & 0.85 & 0.24 & 0.35 & 0.66 & 1.00 & 1.00 & 1.00 \\
\hline HHISIC3 & 118,942 & 0.19 & 0.16 & 0.06 & 0.09 & 0.14 & 0.25 & 0.50 \\
\hline Inst (\%) & 118,942 & $27.9 \%$ & $26.7 \%$ & $0.0 \%$ & $4.1 \%$ & $19.8 \%$ & $46.8 \%$ & $80.4 \%$ \\
\hline Leverage (\%) & 118,942 & $8.8 \%$ & $34.6 \%$ & $-56.5 \%$ & $-11.7 \%$ & $12.5 \%$ & $31.8 \%$ & $60.5 \%$ \\
\hline MFFlow & 118,942 & -0.30 & 0.92 & -1.45 & -0.20 & 0.00 & 0.00 & 0.00 \\
\hline MktShr (\%) & 118,942 & $5.1 \%$ & $12.8 \%$ & $0.0 \%$ & $0.1 \%$ & $0.5 \%$ & $3.3 \%$ & $27.4 \%$ \\
\hline Payout (\%) & 118,942 & $38.1 \%$ & $77.4 \%$ & $0.0 \%$ & $0.0 \%$ & $0.0 \%$ & $50.3 \%$ & $137.0 \%$ \\
\hline $\mathrm{Q}$ & 116,567 & 2.33 & 2.55 & 0.67 & 1.04 & 1.51 & 2.51 & 6.75 \\
\hline R\&D (\%) & 118,942 & $19.0 \%$ & $114.4 \%$ & $0.0 \%$ & $0.0 \%$ & $0.0 \%$ & $4.7 \%$ & $38.2 \%$ \\
\hline
\end{tabular}

the shortfall of actual from potential valuation, scaled by the latter.

In the second specification, we use firm-specific characteristics that are unlikely to be substantially changed by the acquirer. We first include Age, the firm's age (defined as the number of years since a firm's first appearance in CRSP), as this is a characteristic that an acquirer cannot change. Given potential nonlinearities (the effect of Age on growth opportunities, and thus firm value, is likely to be greatest for young firms), we also include the square of Age. We use SalesRank (rank of sales) as a measure of firm size, which likely impacts frontier valuation as it proxies for growth opportunities and diminishing returns to scale. ${ }^{12}$ Size is primarily determined by factors outside the acquirer's control such as firm history. The variables Growth (3-year sales growth) and $M k t S h r$ (market share in the three-digit SIC industry) are likely to be positively correlated with valuation and are also a function of firm history. Further, $R \& D$ (the ratio of $R \& D$ to sales) may affect valuation as it is correlated with growth opportunities, and BetaAsset (the firm's unlevered market beta) captures business cyclicality, which affects the cost of capital; both characteristics are affected by a firm's industry, which is unlikely to be changed by the acquirer. We also employ ATO (asset turnover, the ratio of sales to total assets), as this is primarily determined by asset intensity or the importance of tangible assets in the firm's industry. A high proportion of intangible assets is likely to

\footnotetext{
${ }^{12}$ We use Sales rather than market capitalization as our measure of size, since the latter is directly correlated with our dependent variables.
} 


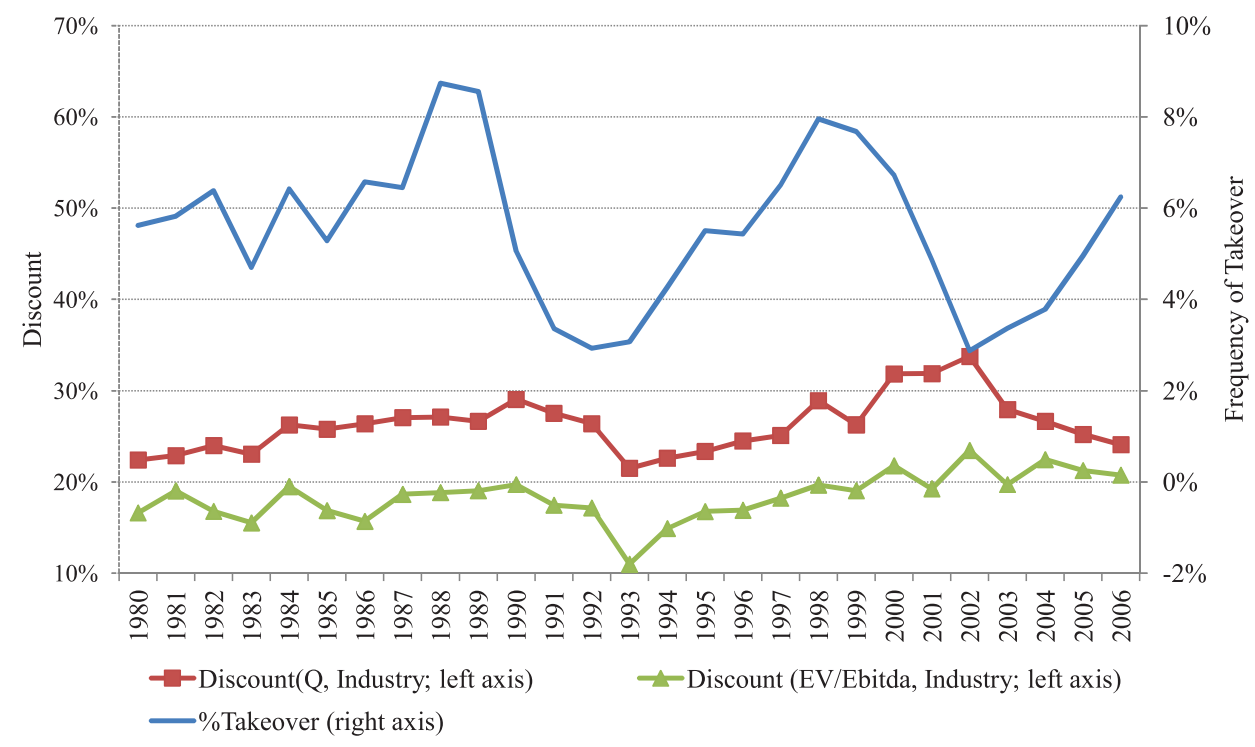

Figure 1. Time series of aggregate discounts and takeover activities. This figure plots the time series (1980 to 2006) of the aggregate Discount (as defined in Table 1, Panel A, the left axis) and the empirical frequency of takeovers (the right axis).

be associated with a low book value and thus a high $Q$.

As stated previously, since an acquirer can alter these $X$ variables to some extent, we only use their tercile ranks among all Compustat firms in a given year (except for Age, where we use the continuous variable as it is strictly exogenous). Our methodology thus allows companies to change the fundamentals within tercile ranges, but not significantly enough to move the firm into a different tercile. For example, an acquirer of a retail company is unlikely to increase $R \& D$ in the target company to the level of pharmaceutical companies, and vice versa. We estimate the frontier values based on firm-specific characteristics using the censored quantile regression technique as specified in (1) and (2), and construct Discount accordingly.

The combination of two valuation metrics and two frontier value specifications yields four Discount measures. Their summary statistics are reported in Table I, Panel B. The $20^{\text {th }}$ percentile values are close to zero by construction, and the mean is $18 \%$ to $28 \%{ }^{13}$ In addition to being necessary to estimate the trigger effect, the "underlying" discount is of independent interest as it measures the potential increase in firm value from a takeover.

Figure 1 plots three graphs. The first two are the time series of the aggregate discount values using the industry frontier value specification, where each

\footnotetext{
13 The mean value is slightly higher than the $16 \%$ found by Habib and Ljungqvist (2005) using a different (parametric) methodology and a larger set of $X$ variables. As we discuss in the text, we are intentionally stringent on the criteria for $X$ variables to ensure that the determinants of the frontier are largely beyond the control of managers and potential acquirers.
} 
annual observation is obtained as the equal-weighted average across all firms during that year. The second is the empirical frequency of takeovers during the sample period, which ranges from about 3\% to above $8 \%$ annually. The aggregate discount and takeover levels tend to move in the same direction, except for 2002 to 2003, when the market crash depressed valuations and reduced firms' ability to finance acquisitions.

As specified in (4), three sets of variables can explain the cross-sectional variation in Discount. The first group comprises the firm fundamental variables $X$. The second group consists of our $Z_{1}$ variables, which measure firm characteristics or policies that affect both the valuation discount and also the takeover likelihood, either by proxying for managerial entrenchment (thus deterring takeovers), or by affecting the ease of takeover execution. The variables Leverage (net debt/book assets) and Payout (dividends plus repurchases divided by net income) both reduce the free cash available to managers and therefore are likely to lessen discounts. In addition, both variables are correlated with business maturity and thus cash flow stability, which facilitates financing of the takeover. As an external governance measure, we include HHISIC3, the Herfindahl index of all firms' sales within the firm's primary three-digit SIC, to capture the degree of product market competition and antitrust concerns, which may impede acquisition. ${ }^{14}$ We also construct the Herfindahl index of the firm's sales by business segment, HHIFirm, as a measure of diversification. Diversification may proxy for an empire-building manager and thus increase the discount; it may also directly deter takeovers since it complicates target integration. Institutional shareholder monitoring is an internal governance mechanism that is likely associated with a lower discount. Institutional ownership concentration also facilitates coordination among shareholders, thus reducing the Grossman and Hart (1980) free-rider problem in takeovers. Indeed, Mikkelson and Partch (1989) and Shivdasani (1993) find that block ownership increases the probability of a takeover attempt. We construct Inst to be the total percentage ownership by institutions from Thomson Reuters. ${ }^{15}$ We also add Amihud, the Amihud (2002) illiquidity measure. Although not a measure

\footnotetext{
${ }^{14}$ Industry concentration could also be a fundamental variable, as industry competitiveness can affect firm profitability. We follow Habib and Ljungqvist (2005) and include it in the category of agency variables. Giroud and Mueller (2010) show that product market competition can discipline management and render corporate governance unimportant.

${ }^{15}$ We do not use the Gompers, Ishii, and Metrick (2003) shareholder rights measure or the Bebchuk, Cohen, and Ferrell (2009) entrenchment index as additional corporate governance variables as they substantially reduce our sample size (by about two-thirds) and skew the sample toward large firms. Since large firms are less likely to be taken over, the sample becomes unrepresentative of the universe of takeover targets. In the Internet Appendix we show that, in the subsamples in which they are available, the entrenchment index is uncorrelated with takeover probability in equilibrium. (An Internet Appendix for this article is available online in the "Supplements and Datasets" section at http://www.afajof.org/supplements.asp.) The shareholder rights index is uncorrelated with takeover probability in equilibrium using the $E V / E b i t d a$ valuation measure. While it is positively correlated with takeover probability using the $Q$ measure, Discount retains its significance. We further show that both indexes are positively correlated with Discount, suggesting that worse governed firms command lower valuations, consistent with Gompers, Ishii, and Metrick (2003) and Bebchuk, Cohen, and Ferrell (2009). Bates, Becher, and Lemmon (2008)
} 
of agency costs, we classify it as a $Z_{1}$ variable as it impacts both Discount and Takeover. Illiquidity directly affects takeover likelihood as it deters toehold accumulation, which in turn affects takeover success rates (Betton and Eckbo (2000)). In addition, it causes firms to trade at a discount (Amihud (2002)).

Finally, the $Z_{2}$ variable affects Discount but has no effect on takeover probability other than through its impact on the discount. We therefore seek a variable that affects the price due to market frictions and is unrelated to either firm fundamentals or managerial resistance. Our chosen instrument is MFFlow, the price pressure created by mutual fund trading that is not induced by information but rather by investor flows. The Appendix describes technical details on the construction of this variable. We assume that, following investor outflows, a mutual fund will be pressured to sell shares in proportion to its current holdings. We consider only mutual funds that have experienced outflows of at least $5 \%$ of total assets, because only extreme outflows are likely to have an impact on pricing, while moderate flow shocks could be absorbed by internal cash or external liquidity providers. Hence, for each stock, this measure is the hypothetical (signed) net selling by all mutual funds that have experienced extreme shocks. Because the impact of a given outflow on prices depends on the stock's liquidity, we scale the dollar outflow by the stock's dollar trading volume. Since order imbalances affect stock prices (see, e.g., Sias, Starks, and Titman (2006) and Coval and Stafford (2007)), MFFlow is significantly and negatively correlated with Discount.

An important feature of our MFFlow measure is that it is constructed not using mutual funds' actual purchases and sales (as in Sias, Starks, and Titman (2006) and Coval and Stafford (2007)), but instead using hypothetical orders projected from their previously disclosed portfolio. Therefore, MFFlow does not reflect mutual funds' discretionary trades possibly based on changes in their views of a stock's takeover vulnerability. Rather, this measure captures the expansion or contraction of a fund's existing positions that is mechanically induced by investor flows to and from the fund. Such flows are in turn unlikely to be driven by investors' views on the takeover likelihood of an individual firm held by the fund, since these views would be expressed through direct trading of the stock. Hence, MFFlow satisfies the exclusion restriction-the econometric requirement of being correlated with the discount but not directly with the probability of a takeover.

Still, a potential concern is that there may be a direct correlation between fund flows and the takeover probability of the firms held by the fund. We can think of three possible reasons for such a correlation. First, some funds may be overweighting future takeover targets (e.g., due to the manager's ability to predict takeovers), and investors' redemption decisions may be affected by this stock selection. Any such effect, however, should attenuate our findings. Funds skilled in identifying takeover targets will exhibit superior performance and thus be more likely to experience inflows than outflows; in turn, such 


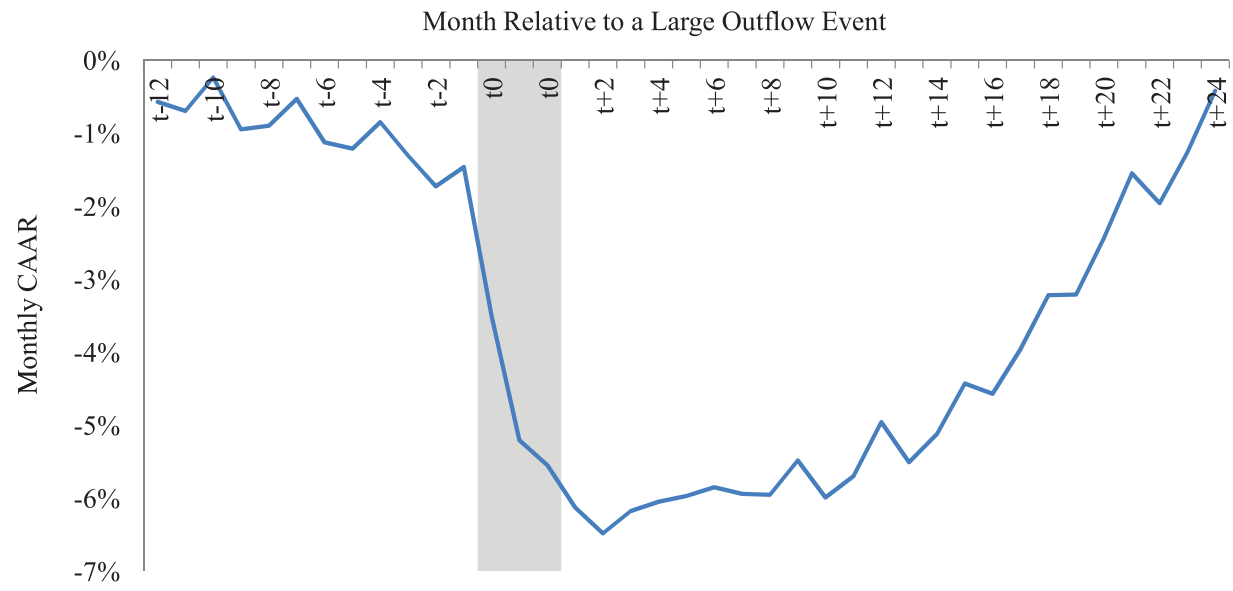

Figure 2. Effect of mutual fund outflows on stock returns. This figure plots the monthly cumulative average abnormal returns (CAAR) of stocks around the event months, where an event is defined as a firm-month observation in which MFFlow falls below the $10^{\text {th }}$ percentile value of the full sample. CAAR is computed over the benchmark of the CRSP equal-weighted index from 12 months before the event to 24 months after. (There are three event months because holdings are only recorded at the quarterly level, while returns are recorded at a monthly frequency.)

inflows should inflate the price of the firms in their portfolio and reduce their takeover likelihood. Second, outflows could be caused by poor fund performance, and it may be that such underperformance is correlated with the takeover vulnerability of the stocks held by the fund. One potential factor is poor fundamentals: a manager with low stock-picking ability may choose weak companies that are likely to be taken over, but also reduce the fund's performance and thus cause outflows. We address this concern by controlling for observable firm fundamentals in the takeover likelihood equation, and also by showing that stocks subject to large MFFlow do not exhibit poor performance beforehand, contradicting the concern that poor stock performance may have led to the outflows. Third, mutual funds specializing in a particular industry may experience flows that are correlated with shocks to both the valuation and the takeover activities in the industry. For example, the bursting of the technology bubble sparked sector consolidation as well as outflows from technology mutual funds. We thus exclude sector mutual funds in constructing the MFFlow measure. ${ }^{16}$ In addition, we use year fixed effects to control for any aggregate shocks to both takeover activity and fund flows in a particular year.

Figure 2 illustrates the magnitude and persistence of the effect of mechanically driven mutual fund redemptions on stock prices. Following Coval and Stafford (2007), we define an "event" as a firm-month in which MFFlow falls below the $10^{\text {th }}$ percentile value of the full sample. We then trace out the cu-

\footnotetext{
16 These funds represent $8.5 \%$ of all funds in our sample, and $8.7 \%$ of the aggregate flows (in unsigned absolute magnitude) to and from equity mutual funds. Results are qualitatively unchanged when including these funds.
} 
mulative average abnormal returns $(C A A R)$ over the CRSP equal-weighted index from 12 months before the event to 24 months after. (There are 3 event months because holdings are only recorded at the quarterly level, while returns are recorded at a monthly frequency). Figure 2 shows that there is no significant decline in stock price prior to the event. Upon the event, the price pressure effects are both significant in magnitude and long-lasting, persisting for over a year. Equally important, they are temporary rather than fundamental, with the price recovering by the end of the $24^{\text {th }}$ month. The duration effect is similar to that found by Coval and Stafford (2007). ${ }^{17}$

\section{Empirical Results}

\section{A. Determinants of Discount and Takeover without Feedback}

As a first step and for comparison with later results, we estimate (4) and (5) without incorporating the anticipation effect. In this setting, the two equations are estimated separately. Table II reports the determinants of Discount and Takeover, for all four measures of Discount.

We first describe the results in Panel B, which tabulates the determinants of Discount. Both high leverage and high payout should mitigate the agency problems of free cash flow and reduce the discount. Our empirical results are consistent with this hypothesis for Leverage, although the results for Payout are more mixed. Firms with more concentrated businesses (high HHIFirm) are associated with a lower discount, consistent with the large literature on the diversification discount. Industry concentration (proxied by HHISIC3) has a negative effect on Discount, indicating that the benefits from market power outweigh the lack of product market discipline. Some variables, such as Inst, have different effects on Discount depending on whether the frontier is industry- or firm-specific. This dichotomy implies that stocks with high institutional ownership tend to have high valuations relative to their fundamental variables, but low valuations relative to other firms in the same industry. Consistent with Amihud (2002), illiquidity increases the discount. Finally, our instrument, MFFlow, is significantly associated with lower discounts across all four specifications.

We now turn to the Takeover equation in Panel A, which illustrates the responsiveness of the probability of acquisition to Discount. In terms of marginal probabilities, a one percentage point increase in Discount is associated with a one to three basis point (i.e., a 0.01 to 0.03 percentage point) increase in takeover probability, and an interquartile change in Discount is associated with a 0.4 to 1.6 percentage point increase, out of an unconditional probability of $6.2 \%$. While a number of prior papers find no relationship between takeovers and raw valuation, this coefficient is highly statistically significant. The result

\footnotetext{
${ }^{17}$ Since mutual fund outflows are correlated, approximately $30 \%$ of the "events" are followed by a consecutive "event" in the next quarter. Figure 2 seeks to illustrate the total impact of a large outflow event. Restricting the figure to only the first "event" in a sequence leads to a very similar pattern: stock prices remain depressed for over a year, with full correction after 2 years.
} 


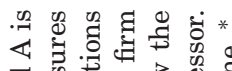

उ) कू क्ष

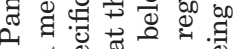

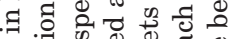
웡 बाँ

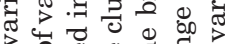

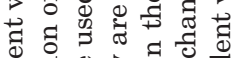
品

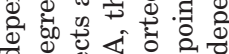
\&

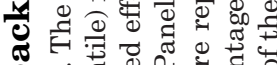
\%

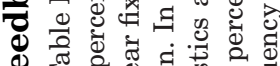

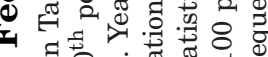

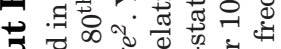

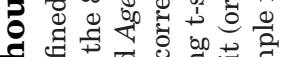

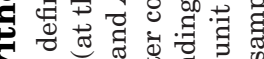

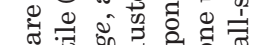
के

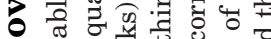
8.

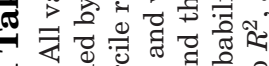
- 0 政

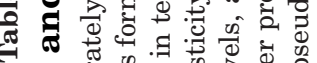

$\vec{z}$. \$) के

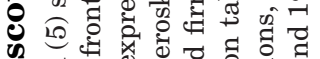

可

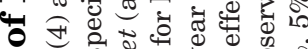

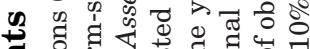
I 0 है ब. व ह (1) 牙 . कु a 년 कु वै 0 कू

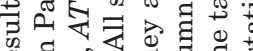
कू की

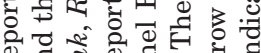
क्षे क्षै สำ 4 वृ

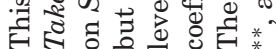

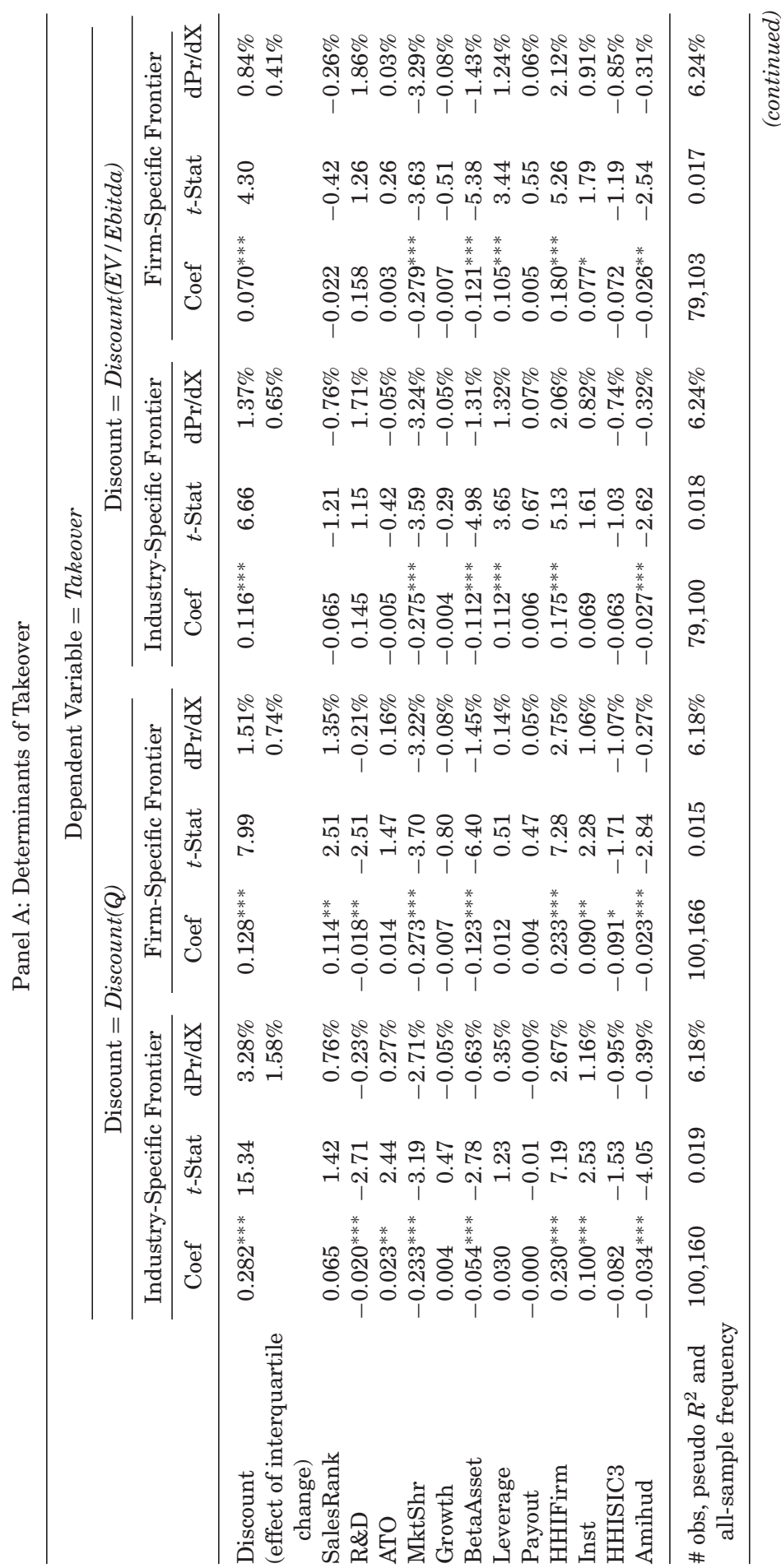




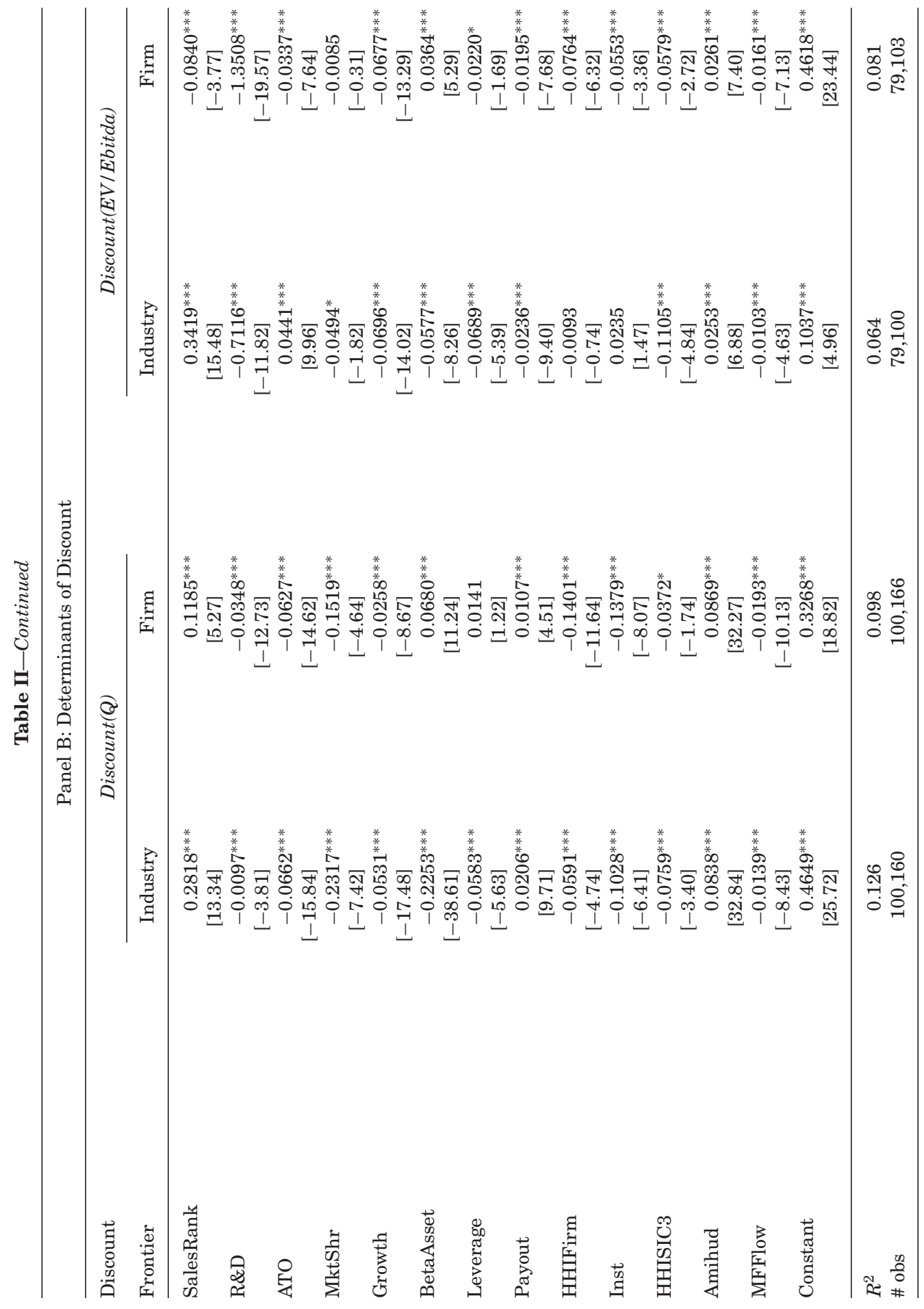


is consistent with the hypothesis that the discount to potential value, rather than raw valuation, motivates acquisitions. ${ }^{18}$ Nevertheless, the economic magnitude is modest, especially when using $E V / E b i t d a$. One important source of the modest effect is the endogeneity of the discount, which is shrunk by the prospects of a takeover. Such an anticipation effect attenuates the relation between takeover and valuation. The next section shows that, when feedback is taken into account, the economic significance rises substantially.

\section{B. Determinants of Takeover and Discount with Feedback}

\section{B.1. The Trigger Effect}

We now analyze the simultaneous system of (8) and (9). We first investigate the effect of the underlying discount, Discount ${ }^{0}$, on takeover probability that would prevail if the former were not affected by the latter, that is, we estimate the trigger effect, controlling for the anticipation effect. The trigger effect therefore measures the "true" importance of the discount for takeover attractiveness. The results are reported in Table III.

Compared to the estimates in Table II, the coefficients on Discount are orders of magnitude higher in all four specifications. Table III shows that a one percentage point increase in Discount would lead to a statistically significant 12 to 16 basis point increase in Takeover probability if Discount did not shrink in anticipation of a takeover. An interquartile change in Discount is associated with a 5.7 to 7.6 percentage point increase in Takeover probability, economically significant relative to an unconditional probability of $6.2 \%$. The sensitivity is higher using the Discount measure derived from industry-specific value frontiers, indicating that acquirers are more attracted to firms with low valuations compared to their industry peers.

The table also presents the results of two Wald tests. The first is a Stock and Yogo (2005) weak instrument test, which rejects the hypothesis that the instruments are weak. The second evaluates the exogeneity of the system, that is, whether Discount is exogenous to shocks in Takeover. The null is rejected at less than the $1 \%$ level in all four specifications. The second test result, combined with the difference in the Discount coefficient between Tables II and III, highlights the need to control for endogeneity by using an instrument when estimating the trigger effect. Doing so shows that prices are a far more important driver of takeover activities than implied by the equilibrium correlation between the two variables.

\section{B.2. The Anticipation Effect}

\footnotetext{
${ }^{18}$ Replacing Discount with raw valuation leads to an interquartile response of 0.04 (using $E V / E b i t d a$ ) and 0.65 (using Q) percentage points in takeover frequency. Both values, though significant in our large sample, are considerably lower than those using Discount. This economically insignificant coefficient is consistent with prior empirical findings.
} 


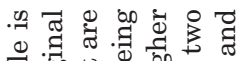
党. 蛋 $>0$.

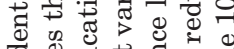

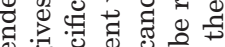
ब. \&

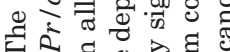
Eิ

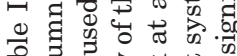

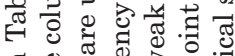

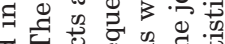
ठ

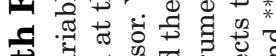

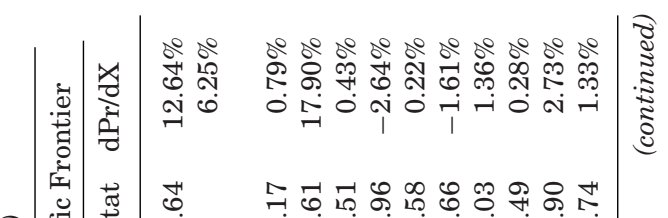
ఫิ

学 II

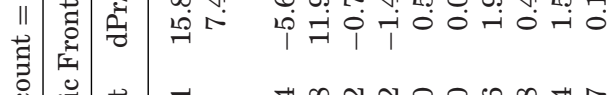

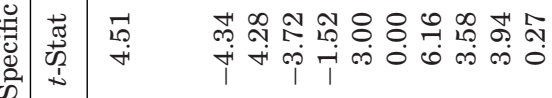

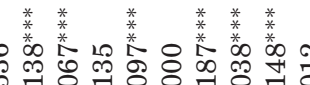

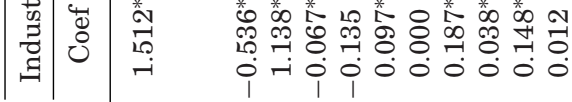

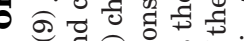
प्र

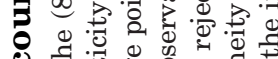

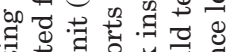

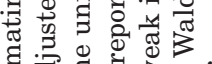

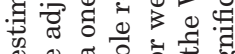
\% घี

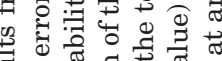
च 要

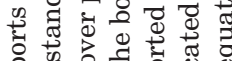

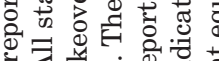

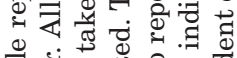

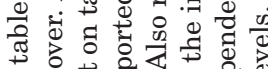

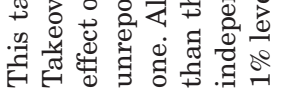

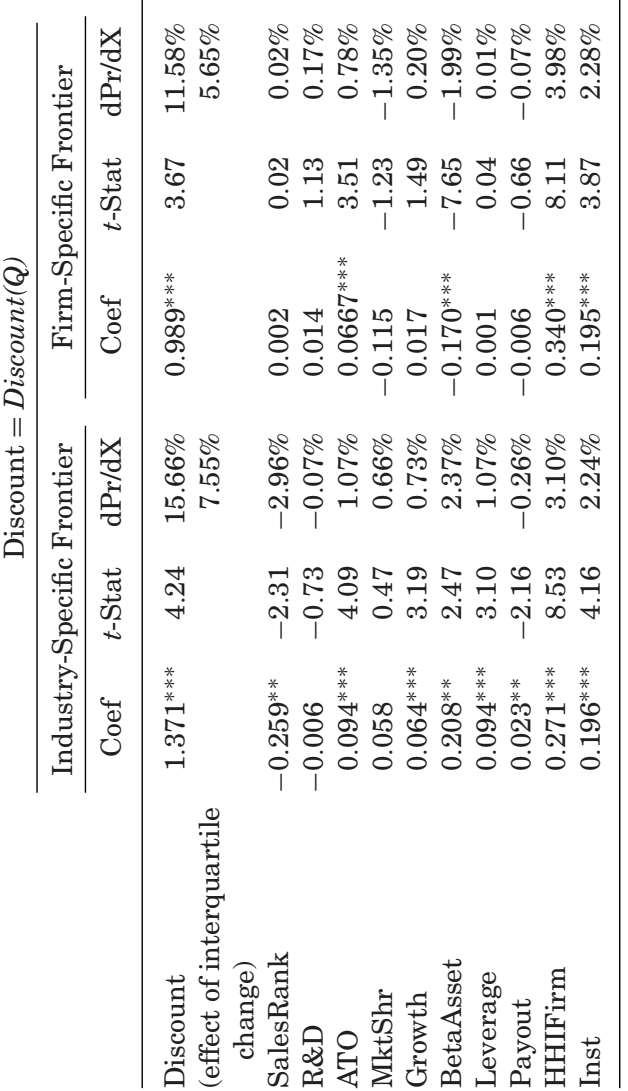




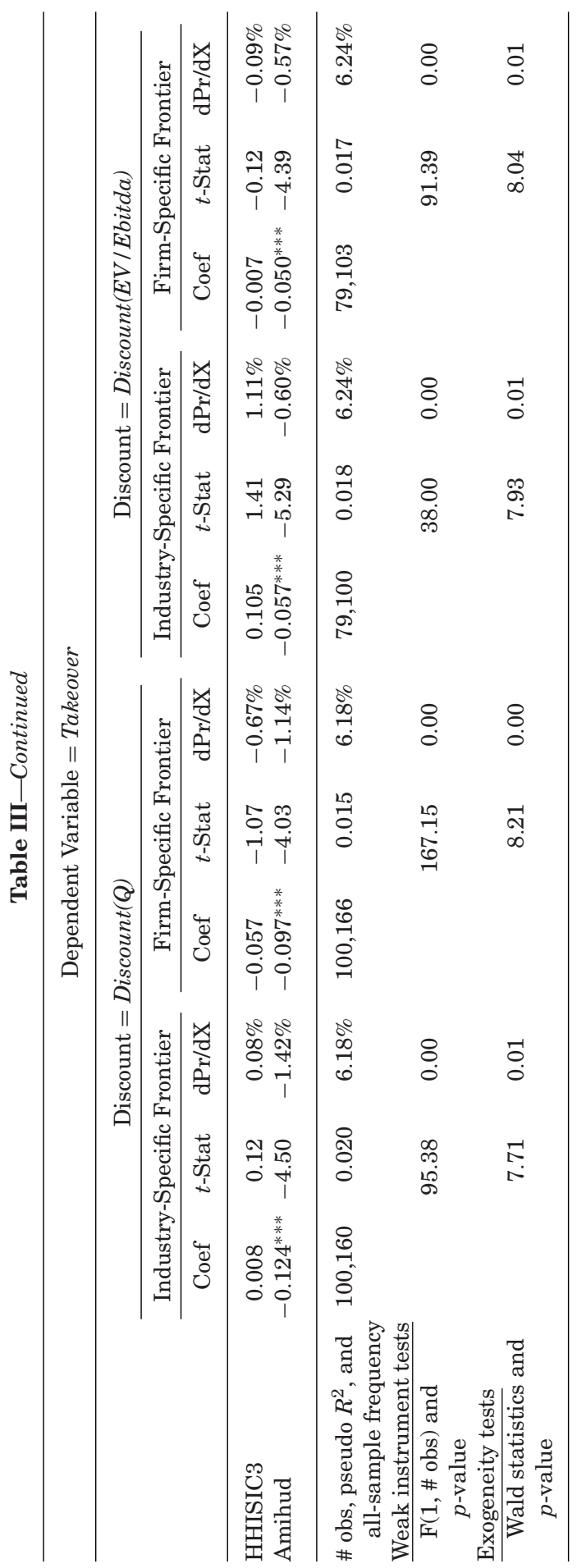


Table III quantifies the trigger effect-the impact of discount changes on the probability of a takeover. In this section, we attempt to estimate the extent to which shocks to takeover probability affect the discount, for example, due to the anticipation effect.

One way to identify the effect of takeover vulnerability (i.e., Takeover ${ }^{*}$ ) on Discount would be to use an instrumental variable that impacts Takeover* but does not affect Discount directly. Firm-specific variables usually do not satisfy this exclusion restriction. Valid instruments could come from the "supply side," such as capital inflows to buyout funds or interest rates that proxy for the ease of financing. However, such instruments suffer from low power because they fail to generate variation in the cross-section.

We therefore adopt a different approach. We identify the effect of the shocks to takeover vulnerability on Discount (i.e., the $\delta$ term in equation (8) by using the intermediate and final outputs from estimating equation (9)). Recall equation (11),

$$
\widetilde{\text { Discount }}=\delta \xi+\eta^{\prime},
$$

which shows that the anticipation coefficient $\delta$ is a linear projection of the residual discount (defined in (11)) on $\xi$, the residual in the takeover equation. We can therefore construct a $\widehat{\delta}$ estimate by regressing the empirical analog of residual discount (Discount) on the empirical analog of $\xi(\widehat{\xi})$. The empirical analog Discount is readily available from (11). For the empirical analog $\widehat{\xi}$, we adopt the "generalized residual" for discrete response models as proposed by Gourieroux et al. (1987),

$$
\widehat{\xi}=\frac{[\text { Takeover }-\widehat{\operatorname{Pr}}(\text { Takeover })] \widehat{\operatorname{Pr}}(\text { Takeover })}{\widehat{\operatorname{Pr}}(\text { Takeover })[1-\widehat{\operatorname{Pr}}(\text { Takeover })]}
$$

where $\widehat{\operatorname{Pr}}($ Takeover $)$ and $\widehat{\operatorname{Pr}}^{\prime}($ Takeover $)$ represent the estimated probability and density (derivative of probability) of Takeover, respectively. Assuming that error disturbances are drawn from normal distributions, the above expression becomes

$$
\widehat{\xi}=\frac{[\text { Takeover }-\Phi(\widehat{u})] \phi(\widehat{u})}{\Phi(\widehat{u})[1-\Phi(\widehat{u})]}
$$

where $\widehat{u}=\widehat{\mu}_{1}$ Discount $+\widehat{\mu}_{2} X+\widehat{\mu}_{3} Z_{1}$, with $\Phi$ and $\phi$ representing the cumulative distribution function and the density function of the standard normal distribution, respectively.

The results from all four specifications are reported in Table IV. Our estimates for the coefficient $\delta$ are uniformly negative, as expected, and highly statistically significant. The economic magnitude of the coefficients is not readily interpretable because $\xi$ is a shock to the propensity of takeover, which does not have a natural unit. One way to interpret the economic significance of our results is to consider the effect of a one percentage point increase in the probability of a takeover on the discount. This is given by $[d D i s c o u n t / d \xi] /$ 


\section{Table IV}

\section{The Feedback Effect from Takeover to Discount}

This table reports the estimation of the system (8)-(9) through a regression of residual Discount from equation (11) on shocks to Takeover from equation (14). All standard errors are adjusted for heteroskedasticity and correlation double-clustering at the year and firm levels, as well as for the variation from the first-stage estimation. The associated t-statistics are reported in the brackets. ${ }^{*},{ }^{* *}$, and ${ }^{* * *}$ indicate statistical significance at the $10 \%, 5 \%$, and $1 \%$ levels.

\begin{tabular}{lccccc}
\hline \multirow{2}{*}{$\begin{array}{l}\text { Residual Discount } \\
\text { Frontier }\end{array}$} & \multicolumn{2}{c}{ Discount $(Q)$} & & \multicolumn{2}{c}{ Discount(EV/Ebitda) } \\
\cline { 2 - 3 } \cline { 5 - 6 } & Industry & Firm & & Industry & Firm \\
\hline \multirow{2}{*}{ (Shocks in Takeover*) } & $-0.163^{* * *}$ & $-0.140^{* * *}$ & & $-0.266^{* * *}$ & $-0.193^{* * *}$ \\
& {$[-32.40]$} & {$[-18.66]$} & & {$[-32.92]$} & {$[-33.96]$} \\
\# obs & 100,160 & 100,166 & & 79,100 & 79,103 \\
$R^{2}$ & 0.040 & 0.046 & & 0.109 & 0.048 \\
\hline
\end{tabular}

$[d \operatorname{Pr}($ Takeover $) / d \xi]$. From Table IV, using Discount $(Q$, Industry), we have $d$ Discount $/ d \xi=-0.163$. Since $\operatorname{Pr}($ Takeover $)$ is nonlinear in $\xi, d \operatorname{Pr}($ Takeover $) / d \xi$ varies with $\operatorname{Pr}($ Takeover $)$. Taking the average firm, for which $\operatorname{Pr}($ Takeover $)=$ $6.2 \%$, we obtain $d \operatorname{Pr}($ Takeover $) / d \xi=0.136$ and thus a one percentage point increase in the probability of a takeover is expected to reduce the discount by approximately $1.2(=0.163 / 0.136)$ percentage points for the average firm.

Based on this estimation, we can now assess the extent to which the coefficient $\delta$ is likely to capture the anticipation effect versus other sources of endogeneity. Given the average takeover premium of approximately $40 \%$, a one percentage point increase in takeover probability should reduce the discount by 0.4 percentage points due to the anticipation effect. Therefore, for the average firm, our estimated $\delta$ is larger than what can be solely attributed to the anticipation effect. The remaining $0.8(=1.2-0.4)$ percentage points may stem from other sources. First, a more negative $\delta$ might be capturing the fact that an increase in the probability of a takeover in a given year leads to higher takeover probabilities in future years and hence to a greater reduction in the discount. Indeed, a simple calculation shows that, for the average firm, a one percentage point increase in the probability of takeover in a given year can lead to a 1.2 percentage point decrease in the discount if it also leads to an increase in takeover probabilities in future years. ${ }^{19}$ Second, a more negative $\delta$ may result from omitted variables, for example, a firm-specific technological shock may increase the probability that the firm becomes a takeover target (due to new potential synergies) and decrease the discount (due to the increase in firm valuation).

An interesting implication of the quantification of an anticipation effect is that it allows us to decompose the determinants of a firm's discount into two parts. The first part is the direct effect of certain firm characteristics or policies

\footnotetext{
19 The full magnitude of the estimated $\delta$ could be accounted for if we allow the anticipation effect to incorporate the probability of receiving a takeover bid in all future years (discounted appropriately). Since our formal analysis is at the firm-year level, it is limited to capturing the relation between the discount and takeover shocks in the following year.
} 
on valuation; the second is the indirect effect of such characteristics or policies via their impact on takeover probability. To illustrate this point, consider the variable Amihud. From Table II, we see that, using Discount (Q, Industry), a one unit increase in Amihud is associated with a 8.38 percentage point increase in Discount. We also learn from Table III that a one unit increase in Amihud decreases takeover propensity (measured by Takeover ${ }^{*}$ ) by -0.124 , which, according to Table IV, leads to an increase of $1.69(=-0.124 \times(-0.136))$ percentage points in Discount. Hence, the overall effect of Amihud on Discount8.38 percentage points - can be decomposed into an indirect effect via the impact on takeover likelihood (1.69 percentage points) and a direct effect on price (6.69 percentage points). Thus, while it is well known that illiquidity reduces a firm's market valuation, this decomposition demonstrates that approximately $20 \%$ of this effect arises indirectly through the reduced takeover probability.

We are unable to perform a similar decomposition using governance variables (such as the Gompers, Ishii, and Metrick (2003) shareholder rights measure or the Bebchuk, Cohen, and Ferrell (2009) entrenchment index) because they are only available for one-third of our sample, reducing the power of our tests (see also footnote 15). For a similar reason, our methodology estimates a single trigger effect and a single anticipation effect across the whole sample; we are unable to make these effects depend on firm governance. There is also another reason we are unable to allow the anticipation effect to differ across governance, or any other firm characteristic (even if such data were available for the full sample)_any such characteristic should also belong to $Z_{1}$ (a vector of variables that proxy for managerial agency), which enters in both equations (8) and (9). Both Discount and $\widehat{\xi}$ (the estimated shock to takeover) are thus, by construction, orthogonal to $Z_{1}$ and hence to proxies of governance. ${ }^{20}$

\section{Additional Analyses}

\section{A. Discount, Takeover Premium, and Acquirer Return}

In equilibrium, we would expect our discount measure to be positively correlated with the premium paid to the target, as well as with the acquirer return. A higher discount implies greater gains from a corrective takeover. Thus, as long as the target has some bargaining power, it should capture a proportion of these gains in the form of a higher premium. Similarly, as long as the acquirer has some bargaining power, it should also realize a higher gain when the discount is higher.

As is standard in the literature, we calculate Premium as the percentage increase in the target's stock price over the $[-60,0]$ window relative to the announcement date, ${ }^{21}$ and AcquirerRET as the $[-1,+1]$ percentage increase in the acquirer's stock price above the CRSP value-weighted index. We find

\footnotetext{
20 The idea of making coefficients dependent on other parameters is feasible in standard regressions but is not possible here because we have a "residual on residual" regression rather than a standard regression, and by construction the residuals are orthogonal to the covariates.

21 The results are qualitatively similar using alternative windows (such as [-40,0]) or the
} 
that both are positively and significantly correlated with Discount: averaging across all four Discount measures, the correlation coefficients are $7.2 \%$ and $1.8 \%$, respectively. By the same logic, a measure of total return from the acquisition (TotalRET $=$ Premium + AcquirerRET) should also be positively correlated with the discount. Indeed, the average correlation coefficient is $7.4 \%$.

To further explore the relation between Discount and the three measures of acquisition return, we run regressions of these measures on Discount, controlling for other determinants of these measures. The regressions appear in the Internet Appendix. The relationship between Discount and both Premium and TotalRET retains its significance in all specifications after the addition of controls. Importantly, while the relationship between Premium and Discount remains highly significant, it is still far from one. This suggests that the acquirer does indeed enjoy part of the gains from buying a discounted target, and is thus consistent with our main result that acquirers are more likely to target discounted firms. The relationship between Discount and Acquirer RET remains significant in the $E V / E b i t d a$ specifications. In the $Q$ regressions, the association is positive but not statistically significant, perhaps because measures of acquirer return are noisy, as is known in the literature. ${ }^{22}$

\section{B. Financially Driven Takeovers}

The results thus far document that takeovers in general are driven by low target valuations. However, certain acquisitions are motivated by other factors, such as synergies or empire building. As such, the trigger effect should be stronger among takeovers that are particularly likely to be valuation-driven. We classify these "financially driven takeovers" as acquisitions that are either leveraged buyouts or undertaken by financial sponsors. Such acquisitions are typically motivated by underperforming current management or market undervaluation, both of which manifest in low market prices. There are a number of reasons for these different motives. First, the aforementioned synergy and empire-building motives for standard acquisitions do not exist to the same degree for LBOs: targets typically remain standalone, and LBO managers are compensated by carried interest above a threshold rate of return. By contrast, for regular corporations, Bebchuk and Grinstein (2009) find a significant link between firm expansion and CEO pay. Second, the LBO structure was designed precisely to correct agency problems. The high debt (compared to standard M\&A deals) imposes discipline on the manager by forcing him to

actual premium paid. The latter is available for a smaller subsample as transaction terms are often missing.

22 There are a number of challenges with measuring acquirer returns accurately. First, there is significant long-run drift after an M\&A announcement (Agrawal, Jaffe, and Mandelker (1992)), making it hard to define an event window that is isolated from other corporate events. Second, the M\&A announcement only reflects the value creation/destruction relative to what was anticipated by the market. Third, the M\&A announcement return implicitly assumes that the counterfactual if the deal had not been undertaken is zero (Prabhala (1997), Li and Prabhala (2007)), which may not be the case. 
disgorge excess cash, and concentrates his equity stake to provide incentives (see, e.g., Jensen (1989) and Edmans (2011)). Third, the literature summarized in Section I.A systematically finds that LBO gains arise from correcting underperformance.

We repeat the trigger effect analysis of Table III, removing all nonfinancially driven takeovers from the sample and report the results in Table $\mathrm{V}$, Panel A. Indeed, the effect of Discount becomes stronger relative to the smaller unconditional probability. An interquartile change in Discount is associated with a $2.2 \%$ increase in the probability of a financially driven takeover. The full-sample probability of such a takeover is $1.3 \%$, compared to the $6.2 \%$ probability of any takeover. In addition, we repeat the anticipation effect analysis of Table IV and report the results in Table V, Panel B.

\section{Robustness Checks}

In this section we report results from further robustness checks. First, we check the sensitivity of our results to the choice of $\alpha=0.20$ as our default percentile for frontier values. As discussed earlier, such a choice reflects the trade-off between reducing the influence of outliers and not underestimating potential values. Higher $\alpha$ values are associated with lower aggregate values of Discount. The Internet Appendix indicates that the correlation of Discount estimates based on different quantile restrictions around $\alpha=0.20$ (our default value) is extremely high (above 0.89 ). Since our analysis is driven by the relative ranking (rather than the absolute level) of Discount, it is not surprising that our results for various $\alpha$ values in the range of $[0.1,0.3]$ are similar to those reported in Tables II to IV.

Second, we estimate the firm-specific frontier using tercile ranks rather than raw measures of the $X$ variables, to allow bidders to change these variables within a given tercile. However, for firms already close to the tercile cutoffs, it is easier for bidders to move these variables into a different tercile. We therefore rerun the analyses excluding firms within $2.5 \%$ of any tercile threshold. The Internet Appendix shows that the results are just as strong as in the full sample in Table III, with an interquartile response of $6.0 \%$ to $7.8 \%$ relative to an unconditional takeover probability of around $6 \%$ for this subsample. A related concern is that, in merger waves (which may be driven by regulatory changes), fundamentals may be particularly likely to change. The Internet Appendix removes both aggregate merger waves (in Panel A) and industry merger waves (in Panel B) and finds that the results are little changed.

Finally, our analysis focuses on bids announced rather than completed, since the target's valuation is likely to have greatest effect on an acquirer's decision to bid. Whether the takeover is subsequently completed often depends on factors unrelated to valuation, for example, antitrust concerns. Nevertheless, we rerun the data defining takeover as completed deals $(76.5 \%$ of the deals in our sample) and tabulate the equivalent of Table III in the Internet Appendix. The results are again qualitatively similar. 
Table V

\section{Financially Driven Takeovers}

This table repeats the analyses in Table III (Panel A) and Table IV (Panel B) but only studies takeovers that are either leveraged buyouts and/or undertaken by financial sponsors. All takeovers are removed from the sample. Other $t$-statistics are reported in the brackets below the coefficient. $*, * *$, and ${ }^{* * *}$ indicate statistical significance at the $10 \%, 5 \%$, and $1 \%$ levels.

\begin{tabular}{|c|c|c|c|c|}
\hline \multicolumn{5}{|c|}{ Panel A: Effect of Discount on Takeover with Feedback } \\
\hline \multirow{2}{*}{$\begin{array}{l}\text { Discount } \\
\text { Frontier }\end{array}$} & \multicolumn{2}{|c|}{$\operatorname{Discount}(Q)$} & \multicolumn{2}{|c|}{ Discount $(E V / E b i t d a)$} \\
\hline & Industry & Firm & Industry & Firm \\
\hline \multirow[t]{2}{*}{ Discount } & $1.481^{* * *}$ & $1.414^{* * *}$ & $1.471^{* * *}$ & $1.448^{* * *}$ \\
\hline & [3.96] & {$[4.06]$} & {$[3.45]$} & {$[3.60]$} \\
\hline$(\mathrm{dPr} / \mathrm{dX})$ & $4.76 \%$ & $4.32 \%$ & $4.69 \%$ & $4.51 \%$ \\
\hline (effect of interquartile change) & $2.29 \%$ & $2.11 \%$ & $2.21 \%$ & $2.23 \%$ \\
\hline \multirow[t]{2}{*}{ SalesRank } & $-0.376^{* * *}$ & $-0.178^{*}$ & $-0.523^{* * *}$ & 0.019 \\
\hline & {$[-3.05]$} & {$[-1.88]$} & {$[-3.21]$} & {$[0.24]$} \\
\hline \multirow[t]{2}{*}{ R\&D } & $0.019^{*}$ & $0.056^{* * *}$ & 0.100 & 1.094 \\
\hline & [1.81] & {$[3.65]$} & {$[0.16]$} & {$[1.36]$} \\
\hline \multirow[t]{2}{*}{ ATO } & $0.146^{* * *}$ & $0.135^{* * *}$ & -0.020 & $0.095^{* * *}$ \\
\hline & {$[6.28]$} & {$[6.37]$} & {$[-0.62]$} & {$[6.26]$} \\
\hline \multirow[t]{2}{*}{ MktShr } & 0.187 & 0.098 & -0.051 & -0.091 \\
\hline & {$[1.22]$} & {$[0.74]$} & {$[-0.44]$} & {$[-0.83]$} \\
\hline \multirow[t]{2}{*}{ Growth } & $0.088^{* * *}$ & $0.050^{* * *}$ & $0.071^{*}$ & $0.074^{*}$ \\
\hline & [3.72] & {$[3.25]$} & [1.67] & [1.81] \\
\hline \multirow[t]{2}{*}{ BetaAsset } & 0.094 & $-0.320^{* * *}$ & -0.118 & $-0.266^{* * *}$ \\
\hline & {$[0.79]$} & {$[-10.43]$} & {$[-1.61]$} & {$[-6.58]$} \\
\hline \multirow[t]{2}{*}{ Leverage } & $0.141^{* * *}$ & 0.034 & $0.214^{* * *}$ & $0.151^{* * *}$ \\
\hline & {$[3.25]$} & {$[0.82]$} & {$[4.37]$} & [3.10] \\
\hline \multirow[t]{2}{*}{ Payout } & -0.009 & 0.002 & $0.050^{* * *}$ & $0.044^{* * *}$ \\
\hline & {$[-0.54]$} & {$[0.12]$} & {$[3.72]$} & {$[3.56]$} \\
\hline \multirow[t]{2}{*}{ HHIFirm } & $0.126^{* *}$ & $0.258^{* * *}$ & 0.061 & $0.169^{* * *}$ \\
\hline & [2.33] & [3.72] & {$[1.24]$} & {$[2.88]$} \\
\hline \multirow[t]{2}{*}{ Inst } & $0.469^{* * *}$ & $0.549^{* * *}$ & $0.234^{* * *}$ & $0.455^{* * *}$ \\
\hline & [8.03] & [8.13] & [2.61] & {$[7.23]$} \\
\hline \multirow[t]{2}{*}{ HHISIC3 } & 0.096 & -0.031 & 0.102 & -0.041 \\
\hline & [1.13] & {$[-0.42]$} & [1.03] & {$[-0.51]$} \\
\hline \multirow[t]{2}{*}{ Amihud } & $-0.134^{* * *}$ & $-0.132^{* * *}$ & $-0.031^{*}$ & $-0.034^{*}$ \\
\hline & {$[-4.08]$} & {$[-4.23]$} & {$[-1.67]$} & {$[-1.88]$} \\
\hline \multirow[t]{2}{*}{ Constant } & $-2.658^{* * *}$ & $-2.382^{* * *}$ & $-1.990^{* * *}$ & $-2.465^{* * *}$ \\
\hline & {$[-33.31]$} & {$[-16.89]$} & {$[-6.75]$} & {$[-15.95]$} \\
\hline \multirow{3}{*}{$\begin{array}{l}\text { Probability of takeover } \\
\text { \# obs } \\
\text { Pseudo } R^{2}\end{array}$} & $1.38 \%$ & $1.38 \%$ & $1.45 \%$ & $1.45 \%$ \\
\hline & 94,802 & 94,808 & 74,901 & 74,904 \\
\hline & 0.037 & 0.032 & 0.041 & 0.040 \\
\hline \multicolumn{5}{|l|}{ Exogeneity tests } \\
\hline \multirow{2}{*}{$\begin{array}{l}\text { Wald statistic } \\
p \text {-value }\end{array}$} & 6.14 & 7.95 & 4.56 & 5.36 \\
\hline & 0.01 & 0.00 & 0.03 & 0.02 \\
\hline
\end{tabular}


Table V—Continued

\begin{tabular}{lccccc}
\hline \multicolumn{4}{c}{ Panel B: The Feedback Effect from Takeover to Discount } \\
\hline Residual Discount & \multicolumn{2}{c}{ Discount(Q) } & & \multicolumn{2}{c}{ Discount(EV/Ebitda) } \\
\cline { 2 - 3 } \cline { 6 - 7 } Frontier & Industry & Firm & & Industry & Firm \\
\hline$\xi$ (Shocks in Takeover) & $-0.272^{* * *}$ & $-0.343^{* * *}$ & & $-0.375^{* * *}$ & $-0.381^{* * *}$ \\
& {$[-12.73]$} & {$[-15.39]$} & & {$[-11.27]$} & {$[-12.24]$} \\
\hline \# obs & 94,802 & 94,808 & & 74,901 & 74,904 \\
$R^{2}$ & $3.59 \%$ & $5.80 \%$ & & $6.55 \%$ & $6.98 \%$ \\
\hline
\end{tabular}

\section{Conclusion}

This paper provides evidence on the real effects of financial markets. Using nonfundamental shocks to market prices-occurring due to nondiscretionary trades by mutual funds that face liquidation pressure from investors' outflows-as an instrumental variable, we show that market prices affect takeover activity. A nonfundamental decrease in the stock price creates a profit opportunity for acquirers and increases the probability that the firm will be taken over. Using an instrument for price changes is essential for identifying this effect since market prices are endogenous and reflect the likelihood of an upcoming acquisition. This may explain the weak relationship between prices and takeover activity found by prior literature. By modeling the relationship between prices and takeovers as a simultaneous system that accounts for anticipation, and by identifying the trigger effect using an instrument, we find a significantly stronger effect of prices on takeovers than previous research.

Our findings have a number of implications for the takeover market. They imply a double-edged sword for the disciplinary effect of takeover threat. The trigger effect suggests that managerial underperformance increases takeover vulnerability to a much greater extent than previously documented. However, the anticipation effect reduces the sensitivity of takeovers to a firm's underlying inefficiency. More generally, the importance of market prices suggests that they are not simply a sideshow but rather affect real economic activity: temporary mispricing can have real consequences by impacting takeover probability.

While our paper demonstrates that market prices have an effect on takeover probability, it is silent on the mechanism behind this effect. It is plausible that market prices have an effect because agents try to learn from them, and, as a result, rely on them when making various decisions. In the context of takeovers, a possible mechanism is that target shareholders use the market price to update their view about the value of the firm and hence demand a price that is related to the market price, while acquirers, who know more about the potential value under their management, identify a profit opportunity when the price goes down and are more likely to launch a bid for the firm. Interestingly, traditional takeover theories do not incorporate such asymmetric information and learning 
from prices. In a framework with symmetric information, if there is free-riding by target shareholders (as in Grossman and Hart (1980)), the bidder must pay the potential value $V^{*}$ regardless of the current price because target shareholders have full bargaining power. Even if the bidder has some bargaining power, it should bargain with the target over the underlying Discount ${ }^{0}$ rather than the observed Discount, since it is the former that represents the potential fundamental value that can be created. Regardless of the source of a high market valuation, it has no effect on takeover likelihood if viewed symmetrically by the bidder and the target. If high valuation is due to positive news about fundamentals (as in Schwert (1996)), both the bidder and the target will agree that a higher takeover price is warranted. Since the superior fundamentals also increase the target's value to the acquirer, the bidder is fully willing to pay the higher price and so the target's attractiveness is unchanged. If high valuation is instead due to mispricing, both the bidder and the target will agree that it should not lead to a high takeover price and so takeover likelihood is again unaffected. Our findings thus suggest the need for new takeover theories to explain why market prices should impact acquisition likelihood.

While our analysis is able to identify the trigger and anticipation effects separately, we are only able to estimate an average trigger effect and an average anticipation effect across the full sample, rather than allow these effects to depend on firm characteristics such as governance, due to limitations of the data and methodology described earlier. In future research it would be interesting to extend our analysis to study the firm-level determinants of these effects. Song and Walkling (2000) show how peer firms' stock price reaction to a merger in their industry depends on characteristics related to the probability of acquisition. While they study a one-time "event-study" effect, our anticipation effect corresponds to the shrinkage of discount that exists in steady state. The trigger effect may similarly depend on firm-level factors.

There are many other settings in which the interaction between the financial market and the real economy is important. These include the impact of market prices on investment decisions, CEO replacement, and other real activities. It is typically difficult to identify a real effect of the financial market since, even if there is a correlation between prices and real activity, it may be driven by an omitted variable that affects both, or it may be attenuated by the anticipation effect. We are able to identify the active role of the financial market by exploring the effects of nonfundamental changes in the price that are not directly correlated with real activity. This insight can be used to explore the empirical relation between financial markets and real activities in these other settings.

\section{Appendix A: Data}

This section details the calculation of the mutual fund price pressure variable. We obtain quarterly data on mutual fund holdings from CDA Spectrum/Thomson and mutual fund flows from CRSP. We remove funds that 
specialize in a single industry and calculate

$$
\text { Outflow }_{j, t}=-F_{j, t} / T A_{j, t-1},
$$

where $j(=1, \ldots, m)$ indexes mutual funds, $t$ represents one quarter, $F_{j, t}$ is the total inflow experienced by fund $j$ in quarter $t$, and $T A_{j, t-1}$ is fund $j$ 's total assets at the end of the previous quarter. We then construct

$$
\text { MFFlow }_{i, t}=\sum_{j=1}^{m} \frac{F_{j, t} s_{i, j, t-1}}{V O L_{i, t}}
$$

for each stock-quarter pair, where $i(=1, \ldots, n)$ indexes stocks and the summation is only over funds $j$ for which Outflow $_{j, t} \geq 5 \%$. The term $V O L_{i, t}$ is total dollar trading volume of stock $i$ in quarter $t$, and

$$
s_{i, j, t}=\frac{S H A R E S_{i, j, t} \times P R C_{i, t}}{T A_{j, t}}
$$

is the dollar value of fund $j$ 's holdings of stock $i$ as a proportion of fund $j$ 's total assets at the end of the quarter. Substitution gives our mutual fund price pressure measure as

$$
\operatorname{MFFlow}_{i, t}=\sum_{j=1}^{m} \frac{F_{j, t} \times S H A R E S_{i, j, t-1} \times P R C_{i, t-1}}{T A_{j, t-1} \times V O L_{i, t}},
$$

where the summation is only over funds $j$ for which Outflow $w_{j, t} \geq 5 \%$. Finally, we sum MFFlow across the four quarters in a given calendar year.

\section{Appendix B: Estimation Procedures}

This section derives the full-information maximum likelihood (FIML) likelihood function for equation (9). The likelihood of an individual takeover in our simultaneous equation model is as follows, omitting the $i$ and $t$ subscripts for brevity:

$$
L=g(\text { Takeover }=1, \text { Discount })^{\text {Takeover }} g(\text { Takeover }=0, \text { Discount })^{1-\text { Takeover }},
$$

where the joint density function $g$ is

$$
g(\text { Takeover }=1, \text { Discount })=\int_{-\mu_{1} \text { Discount }-\mu_{2} X-\mu_{3} Z_{1}}^{\infty} f(\xi, \eta) d \xi,
$$

and

$$
g(\text { Takeover }=0, \text { Discount })=\int_{-\infty}^{-\mu_{1} \text { Discount }-\mu_{2} X-\mu_{3} Z_{1}} f(\xi, \eta) d \xi,
$$

and $f(\xi, \eta)$ is the bivariate density function (assumed to be normal for estimation purposes), which can be expressed as the product of a conditional 
distribution and a marginal distribution:

$$
f(\xi, \eta)=f(\xi \mid \eta) f(\eta) .
$$

The conditional distribution $f(\xi \mid \eta)$ is normal with mean $\rho_{\xi, \eta} \eta / \sigma_{\eta}$ and variance $1-\rho_{\xi, \eta}^{2}$, where $\rho$ and $\sigma$ are the standard notation for correlation coefficient and standard deviation. Therefore the joint density function of (B1), assuming all variables are jointly normal, can be rewritten as

$g($ Takeover $=1$, Discount $)=\Phi\left(\frac{\mu_{1} \text { Discount }+\mu_{2} X+\mu_{3} Z_{1}+\rho_{\xi, \eta} \eta / \sigma_{\eta}}{\sqrt{1-\rho_{\xi, \eta}^{2}}}\right) \phi\left(\frac{\eta}{\sigma_{\eta}}\right)$,

and $\Phi$ and $\phi$ are the cumulative probability and density functions of the standard normal distribution. Equation (B2) can be rewritten analogously. Combining all equations, we arrive at the log likelihood for a takeover on a firm-year observation:

$l_{i, t}=$ Takeover $_{i, t} \ln \left[\Phi\left(u_{i, t-1}\right)\right]+\left(1-\right.$ Takeover $\left._{i, t}\right) \ln \left[1-\Phi\left(u_{i, t-1}\right)\right]-\ln \left(\sigma_{\eta}\right)-\frac{\eta^{2}}{2 \sigma_{\eta}^{2}}$,

where

$$
\begin{aligned}
& u=\frac{\mu_{1} \text { Discount }+\mu_{2} X+\mu_{3} Z_{1}+\rho_{\xi, \eta} \eta / \sigma_{\eta}}{\sqrt{1-\rho_{\xi, \eta}^{2}}}, \\
& \eta=\text { Discount }-\gamma_{1} Z_{1}-\gamma_{2} Z_{2} .
\end{aligned}
$$

The estimation methodology is FIML. It is "full information" because it employs the full information about the joint distribution of $f(\xi, \eta)$ by using the conditional distribution $f(\xi \mid \eta)$ and the marginal distribution $f(\eta)$ simultaneously. Further, it is a "maximum likelihood" estimator and thus provides the most efficient estimates (i.e., attains the Cramer-Rao bound) to the extent that the model is correctly specified.

\section{REFERENCES}

Admati, Anat, and Paul Pfleiderer, 2009, The "Wall Street Walk" and shareholder activism: Exit as a form of voice, Review of Financial Studies 22, 2645-2685.

Agrawal, Anup, and Jeffrey F. Jaffe, 2003, Do takeover targets underperform? Evidence from operating and stock returns, Journal of Financial and Quantitative Analysis 38, 721-746.

Agrawal, Anup, Jeffrey F. Jaffe, and Gerson N. Mandelker, 1992, The post-merger performance of acquiring firms: A re-examination of an anomaly, Journal of Finance 47, 1605-1621.

Aigner, Dennis, C.A. Knox Lovell, and Peter Schmidt, 1977, Formulation and estimation of stochastic frontier production function models, Journal of Econometrics 6, 11-37.

Ambrose, Brent, and William Megginson, 1992, The role of asset structure, ownership structure, and takeover defenses in determining acquisition likelihood, Journal of Financial and Quantitative Analysis 27, 575-589.

Amihud, Yakov, 2002, Illiquidity and stock returns: Cross-section and time series effects, Journal of Financial Markets 5, 31-56. 
Andrade, Gregor, Mark Mitchell, and Erik Stafford, 2001, New evidence and perspectives on mergers, Journal of Economic Perspectives 15, 103-120.

Baker, George, and Karen Wruck, 1989, Organizational changes and value creation in leveraged buyouts: The case of the O.M. Scott and Sons Company, Journal of Financial Economics 25, 163-190.

Baker, Malcolm, Xin Pan, and Jeffrey Wurgler, 2012, The effect of reference point prices on mergers and acquisitions, Journal of Financial Economics, forthcoming.

Baker, Malcolm, Richard Ruback, and Jeffrey Wurgler, 2007, Behavioral corporate finance: A survey, in Espen Eckbo, ed. Handbook of Corporate Finance: Empirical Corporate Finance (Elsevier/North Holland, New York).

Baker, Malcolm, Jeremy C. Stein, and Jeffrey Wurgler, 2003, When does the market matter? Stock prices and the investment of equity dependent firms, Quarterly Journal of Economics 118, 969-1006.

Bates, Thomas W., David A. Becher, and Michael L. Lemmon, 2008, Board classification and managerial entrenchment: Evidence from the market for corporate control, Journal of Financial Economics 87, 656-677.

Bebchuk, Lucian A., Alma Cohen, and Allen Ferrell, 2009, What matters in corporate governance? Review of Financial Studies 22, 787-827.

Bebchuk, Lucian A., and Yaniv Grinstein, 2009, Firm expansion and CEO pay, Working paper, Harvard University.

Betton, Sandra, and B. Espen Eckbo, 2000, Toeholds, bid-jumps, and expected payoffs in takeovers, Review of Financial Studies 13, 841-882.

Betton, Sandra, B. Espen Eckbo, and Karin Thorburn, 2008, Corporate takeovers, in Espen Eckbo, ed. Handbook of Corporate Finance: Empirical Corporate Finance (Elsevier/North Holland, New York).

Bond, Philip, Alex Edmans, and Itay Goldstein, 2012, The real effects of financial markets, Annual Review of Financial Economics, forthcoming.

Bond, Phillip, Itay Goldstein, and Edward Simpson Prescott, 2010, Market-based corrective actions, Review of Financial Studies 23, 781-820.

Bradley, Michael, Alon Brav, Itay Goldstein, and Wei Jiang, 2010, Activist arbitrage: A study of open-ending attempts of closed-end funds, Journal of Financial Economics 95, 1-19.

Brealey, Richard A., Stewart C. Myers, and Franklin Allen, 2010, Principles of Corporate Finance (McGraw-Hill, New York)

Chen, Qi, Itay Goldstein, and Wei Jiang, 2007, Price informativeness and investment sensitivity to stock price, Review of Financial Studies 22, 1409-1445.

Coval, Joshua, and Erik Stafford, 2007, Asset fire sales (and purchases) in equity markets, Journal of Financial Economics 86, 479-512.

Cremers, Martijn, Vinay B. Nair, and Kose John, 2009, Takeovers and the cross-section of returns, Review of Financial Studies 22, 1409-1445.

Dong, Ming, David Hirshleifer, Scott Richardson, and Siew Hong Teoh, 2006, Does investor misvaluation drive the takeover market? Journal of Finance 61, 725-762.

Dow, James, Itay Goldstein, and Alexander Guembel, 2010, Incentives for information production in markets where prices affect real investment, Working paper, London Business School.

Dow, James, and Gary Gorton, 1997, Stock market efficiency and economic efficiency: Is there a connection? Journal of Finance 52, 1087-1129.

Duffie, Darrell, 2010, Asset price dynamics with slow-moving capital, Journal of Finance 65, 1238-1268.

Eckbo, B. Espen, and Karin S. Thorburn, 2008, Corporate restructuring: Breakups and LBO's, in B. Espen Eckbo, ed. Handbook of Corporate Finance: Empirical Corporate Finance (Elsevier/North Holland, New York).

Edmans, Alex, 2009, Blockholder trading, market efficiency, and managerial myopia, Journal of Finance 62, 2481-2513.

Edmans, Alex, 2011, Short-term termination without deterring long-term investment: A theory of debt and buyouts, Journal of Financial Economics 102, 81-101. 
Edmans, Alex, and Gustavo Manso, 2011, Governance through trading and intervention: A theory of multiple blockholders, Review of Financial Studies 24, 2395-2428.

Fishman, Michael, and Kathleen Hagerty, 1992, Insider trading and the efficiency of stock prices, RAND Journal of Economics 23, 106-122.

Giroud, Xavier, and Holger M. Mueller, 2010, Does corporate governance matter in competitive industries? Journal of Financial Economics 95, 312-331.

Goldstein, Itay, and Alexander Guembel, 2008, Manipulation and the allocation role of prices, Review of Economic Studies 75, 133-164.

Gompers, Paul, Joy Ishii, and Andrew Metrick, 2003, Corporate governance and equity prices, Quarterly Journal of Economics 118, 107-155.

Gourieroux, Christian, Alain Monfort, Eric Renault, and Alain Trognon, 1987, Generalized residuals, Journal of Econometrics 34, 4-32.

Grossman, Sanford J., and Oliver D. Hart, 1980, Takeover bids, the free-rider problem, and the theory of the corporation, Bell Journal of Economics 11, 42-64.

Habib, Michael, and Alexander Ljungqvist, 2005, Firm value and managerial incentives: A stochastic frontier approach, Journal of Business 78, 2053-2094.

Hackbarth, Dirk, and Erwan Morellec, 2008, Stock returns in mergers and acquisitions, Journal of Finance 63, 1213-1252.

Hoberg, Gerard, and Gordon M. Phillips, 2010, Real and financial industry booms and busts, Journal of Finance 65, 45-86.

Holmstrom, Bengt, and Jean Tirole, 1993, Market liquidity and performance monitoring, Journal of Political Economy 101, 678-709.

Hunt-McCool, Janet, Samuel Koh, and Bill Francis, 1996, Testing for deliberate underpricing in the IPO premarket: A stochastic frontier approach, Review of Financial Studies 9, 12511269 .

Jensen, Michael C., 1989, Eclipse of the public corporation, Harvard Business Review 67, 61-74.

Jensen, Michael C., 1993, The modern industrial revolution, exit, and the failure of internal control systems, Journal of Finance 48, 831-880.

Jensen, Michael C., and Richard S. Ruback, 1983, The market for corporate control: The scientific evidence, Journal of Financial Economics 11, 5-50.

Kaplan, Steven N., 1989, The effects of management buyouts on operating performance and value, Journal of Financial Economics 24, 217-254.

Koenker, Roger, and Gilbert Bassett, 1978, Regression quantiles, Econometrica 46, 33-50.

Kumbhakar, Subal, and Knox Lovell, 2000, Stochastic Frontier Analysis (Cambridge University Press, Cambridge, MA).

Li, Kai, and N. R. Prabhala, 2007, Self-selection models in corporate finance, in Espen Eckbo, ed. Handbook of Corporate Finance: Empirical Corporate Finance (Elsevier/North Holland, New York).

Lichtenberg, Frank R., and Donald Siegel, 1990, The effects of leveraged buyouts on productivity and related aspects of firm behavior, Journal of Financial Economics 27, 165-194.

Manne, Henry, 1965, Mergers and the market for corporate control, Journal of Political Economy $73,110-120$.

Marris, Robin, 1964, The Economic Theory of Managerial Capitalism (Macmillan, London).

Mikkelson, Wayne, and Megan Partch, 1989, Managers' voting rights and corporate control, Journal of Financial Economics 25, 163-190.

Morck, Randall, Andrei Shleifer, and Robert Vishny, 1990, The stock market and investment: Is the market a sideshow? Brookings Papers on Economic Activity 2, 157-202.

Muscarella, Chris J., and Michael R. Vetsuypens, 1990, Efficiency and organizational structure: A study of reverse LBOs, Journal of Finance 45, 1389-1413.

Palepu, Krishna, 1986, Predicting takeover targets: A methodological and empirical analysis, Journal of Accounting and Economics 8, 3-35.

Powell, James, 1984, Least absolute deviations estimation for the censored regression model, Journal of Econometrics 25, 303-325.

Prabhala, N. R., 1997, Conditional methods in event-studies and an equilibrium justification for using standard event-study methods, Review of Financial Studies 10, 1-38. 
Rhodes-Kropf, Matthew, David Robinson, and S. Viswanathan, 2005, Valuation waves and merger activity: The empirical evidence, Journal of Financial Economics 77, 561-603.

Rivers, Douglas, and Quang Vuong, 1988, Limited information estimators and exogeneity tests for simultaneous probit models, Journal of Econometrics 39, 347-366.

Schwert, G. William, 1996, Markup pricing in mergers and acquisitions, Journal of Financial Economics 41, 153-192.

Shivadasani, Anil, 1993, Board composition, ownership structure, and hostile takeovers, Journal of Accounting and Economics 16, 167-198.

Shleifer, Andrei, and Robert Vishny, 2003, Stock market driven acquisitions, Journal of Financial Economics 70, 295-311.

Sias, Richard, Laura T. Starks, and Sheridan Titman, 2006, Changes in institutional ownership and stock returns: Assessment and methodology, Journal of Business 79, 2869-2910.

Smith, Abbie J., 1990, Corporate ownership structure and performance: The case of management buyouts, Journal of Financial Economics 27, 143-164.

Song, Moon, and Ralph Walkling, 2000, Abnormal returns to rivals of acquisition targets: A test of the "acquisition probability hypothesis," Journal of Financial Economics 55, 143-171.

Stein, Jeremy, 1996, Rational capital budgeting in an irrational world, Journal of Business 69, 429-455.

Stock, James, and Motohiro Yogo, 2005, Testing for weak instruments in linear IV regression, in James Stock and Donald Andrews, eds. Identification and Inference for Econometric Models: A Festschrift in Honor of Thomas Rothenberg (Cambridge University Press, Cambridge).

Subrahmanyam, Avindar, and Sheridan Titman, 1999, The going-public decision and the development of financial markets, Journal of Finance 54, 1045-1082. 